\title{
Genome-Wide Characterization, Expression Profile Analysis of WRKY Family Genes in Santalum album and Functional Identification of Their Role in Abiotic Stress
}

\author{
Haifeng Yan ${ }^{1,+}{ }^{\dagger}$ Mingzhi $\mathrm{Li}^{2,+}$, Yuping Xiong ${ }^{3, \dagger}{ }^{+}$Jianming $\mathrm{Wu}^{1, *}$, Jaime A. Teixeira da Silva ${ }^{4, *}$ \\ and Guohua $\mathrm{Ma}^{3, * \text { (D) }}$ \\ 1 Sugarcane Research Institute, Guangxi Academy of Agricultural Sciences, Nanning 530007, China; \\ gstsyhf@163.com \\ 2 Biodata Biotechnology Co., Ltd, Hefei 230031, China; Limzhi87@163.com \\ 3 Guangdong Provincial Key Laboratory of Applied Botany, South China Botanical Garden, the Chinese \\ Academy of Sciences, Guangzhou 510650, China; xiongyuping@scbg.ac.cn \\ 4 P.O. Box 7, Miki-cho Post Office, Miki-cho, Ikenobe 3011-2, Kagawa-ken 761-0799, Japan \\ * Correspondence: wujianming2004@126.com (J.W.); jaimetex@yahoo.com (J.A.T.d.S.); magh@scib.ac.cn (G.M.) \\ + These authors contributed equally to this work.
}

Received: 9 October 2019; Accepted: 5 November 2019; Published: 13 November 2019

\begin{abstract}
WRKY proteins are a large superfamily of transcription factors that are involved in diverse biological processes including development, as well as biotic and abiotic stress responses in plants. WRKY family proteins have been extensively characterized and analyzed in many plant species, including Arabidopsis, rice, and poplar. However, knowledge on WRKY transcription factors in Santalum album is scarce. Based on S. album genome and transcriptome data, 64 SaWRKY genes were identified in this study. A phylogenetic analysis based on the structures of WRKY protein sequences divided these genes into three major groups (I, II, III) together with WRKY protein sequences from Arabidopsis. Tissue-specific expression patterns showed that 37 SaWRKY genes were expressed in at least one of five tissues (leaves, roots, heartwood, sapwood, or the transition zone), while the remaining four genes weakly expressed in all of these tissues. Analysis of the expression profiles of the 42 SaWRKY genes after callus was initiated by salicylic acid (SA) and methyl jasmonate (MeJA) revealed that 25 and $24 S a W R K Y$ genes, respectively, were significantly induced. The function of SaWRKY1, which was significantly up-regulated by SA and MeJA, was analyzed. SaWRKY1 was localized in the nucleus and its overexpression improved salt tolerance in transgenic Arabidopsis. Our study provides important information to further identify the functions of SaWRKY genes and to understand the roles of SaWRKY family genes involved in the development and in SA- and MeJA-mediated stress responses.
\end{abstract}

Keywords: WRKY transcription factor; sandalwood; SA (salicylic acid); MeJA (methyl jasmonate); salt tolerance

\section{Introduction}

Transcription factors (TFs) are proteins that can bind to specific DNA target sites and activate and/or repress transcription of their target genes [1]. Among them, WRKY TFs are mainly found in plants, while a few are found in the protist Giardia lamblia and the slime mold Dictyostelium discoideum [2,3]. In green plants, the WRKY family is the eighth largest TF family following ethylene responsive factor (ERF), $\mathrm{C}_{2} \mathrm{H}_{2}$, basic helix-loop-helix (bHLH), myeloblastosis (MYB), NAC (NAM, ATAF1/2 and CUC2), 
basic leucine zipper (bZIP), and MYB-related families [4] (http://planttfdb.cbi.pku.edu.cn/). The first WRKY TF, SWEETPOTATO FACTOR1 (SPF1), was identified in sweet potato (Ipomoea batatas) in 1994 [5]. Since then, numerous WRKY genes have been identified after genome-wide analyses of plants over the past 24 years, including 74 in Arabidopsis (Arabidopsis thaliana) [6], 102 in rice (Oryza sativa) [7], 197 in soybean (Glycine max) [8], and 100 in poplar (Populus trichocarpa and P. tomentosa) [9]. The WRKY family is characterized by the presence of one or two conserved 60 amino acid WRKY domains (WDs), which include the highly conserved WRKYGQK sequence at its $\mathrm{N}$-terminal end and a zinc-finger-like motif at the C-terminal end [6]. The C-terminal WRKY domain is mainly responsible for recognizing the cognate cis-acting $\mathrm{W}$ box elements $(\mathrm{T})(\mathrm{T}) \mathrm{TGAC}(\mathrm{C} / \mathrm{T})$ while the $\mathrm{N}$-terminal end participates in increasing the affinity or specificity of their target sites [6]. Based on the number of WDs and the pattern of their zinc-finger-like motifs, all members of the WRKY family proteins have been classified into three groups I-III [6,10]. WRKY proteins with two WDs fall into group I, whereas proteins with only one WD are assigned to groups II or III. Members of groups I and II have the same type of finger motif, C-C-H-H, while members of group III contain a unique C-C-H-C motif [6]. In addition, group II proteins were further split into five distinct subgroups (IIa, IIlb, IIc, IId and IIe) based on a phylogenetic analysis [6,10]. Apart from the WDs and zinc-finger-like motif, domains for transcobalamin (R) proteins also coexist with WRKY TFs forming R protein-WRKY genes in monocot genomes such as in switchgrass (Panicum virgatum) [11].

WRKY TFs play well-documented roles in regulating various biological processes in plants. The majority of reports demonstrated that numerous WRKY TFs are involved in transcriptional reprogramming associated with the plant's biotic stress response. AtWRKY 3 and AtWRKY4 expression was induced by pathogen infection and salicylic acid (SA), and the T-DNA mutants and transgenic lines of AtWRKY3 and AtWRKY4 suggested that they all had enhanced plant tolerance to necrotrophic pathogens. At the same time, AtWRKY4 negatively regulated plant tolerance to biotrophic pathogens [12]. AtWRKY38 and AtWRKY62, which were induced by pathogen infection and SA treatment, act as negative regulators of plant basal defense [13]. In rice, OsWRKY03 (an AtWRKY29/22 homolog) was involved in SA-dependent or jasmonic acid (JA)-dependent defense signaling cascades and its overexpression upregulated OsNPR1, OsPR1b, phenylalanine ammonia-lyase ZB8 and peroxidase POX22.3 [14]. Furthermore, many reports have shown that WRKY TFs are involved in abiotic stresses, including cold, wounding, heat, ultraviolet light, drought, and salinity $[15,16]$. In addition, WRKY TFs also play important roles in regulating plant developmental processes, such as seed dormancy and germination [17,18], root hair growth [19], and leaf senescence [20].

Santalum album L., commonly known as sandalwood, is a hemiparasitic tropical tree distributed in India, Indonesia, Malaysia, and Australia [21]. It is valued for its essential oil, which is extracted from aromatic heartwood and roots, and is used in aromatherapy, perfumes, cosmetics, medicine and sacred unguents [22,23]. (Z)- $\alpha$-Santalol, (Z)- $\beta$-santalol, (Z)-epi- $\beta$-santalol, (Z)- $\alpha$-exo-bergamotol, and sesquiterpene alcohols are the major components (70\%) of S. album essential oil [23]. Unsustainable demand and exploitation of this slow-growing tree has threatened wild sandalwood populations in their native locations [24]. In an effort to meet the demand for its essential oil, S. album has been planted in Malaysia, Indonesia, Philippines, Northern Australia, and South China [25]. S. album was introduced to South China Botanical Garden in 1970, and is now cultivated in several subtropical regions of China such as Guangdong, Guangxi, Hainan, and Fujian provinces. Various stresses, including low temperature [26] or highly saline or alkaline soil, negatively impact the cultivation and growth of this species. The molecular biology of S. album has made considerable strides in recent years [27], including abiotic stress tolerance. WRKY TFs play important roles in plants against abiotic stress, so characterization and functional analysis of the WRKY family genes in S. album would shed light on the stress mechanisms underlying the involvement of WRKY genes, and it could also serve to breed S. album varieties that are resistant to these stresses. As far as we are aware, there are few reports available on WRKY TFs in S. album. Large-scale available RNA-seq data sets $[26,28,29]$ and genomic data generated recently in S. album [30] might offer additional insight about WRKY genes. 
In this study, a total of 64 SaWRKY genes from S. album were identified, and their conserved motif and tissue expression patterns were analyzed. In order to understand their evolutionary relationship, a phylogenetic tree that combined WRKY proteins from $A$. thaliana was constructed. In addition, the expression profiles of 42 SaWRKY genes under SA and methyl jasmonate (MeJA) treatments were generated using RT-qPCR, while the functional analysis of SaWRKY1 (induced both by SA and MeJA) was carried out by heterologous expression in transgenic $A$. thaliana. The findings of our study will help to understand the roles of SaWRKY genes in SA- and MeJA-mediated pathways and to further identify the functions of this essential gene family in S. album.

\section{Results}

\subsection{Identification and Subcellular Localization of SaWRKYS}

A total of 64 SaWRKY genes named SaWRKY1 to SaWRKY64 were identified (Table 1) by searching the S. album genome and transcriptome datasets using total A. thaliana AtWRKY genes as queries. All of the identified SaWRKY proteins contained at least one highly conserved heptapeptide WRKYGQK domain, while 13 out of 64 SaWRKY proteins contained two WRKYGQK domains. The length of the amino acid sequence in the 64 SaWRKY proteins (Table 1, Table S1) ranged from 121 (SaWRKY45) to 764 (SaWRKY12) amino acids, with an average of 384 amino acids. A C-C-H-H type zinc-finger motif was found in 56 SaWRKY proteins whereas SaWRKY7, 9, 28, 47 and 57 had a C-C-H-C type zinc-finger motif, and other variants of zinc-finger motifs such as C-C-H-T (SaWRKY12, 53), C-C-H-L (SaWRKY25, 51), C-C-H-V (SaWRKY42), C-C-H-Y (SaWRKY45), and C-C-H-S (SaWRKY58), were also found (Table 1).

Table 1. List of SaWRKY genes identified in Santalum album.

\begin{tabular}{|c|c|c|c|c|c|}
\hline Gene Name & ORF (aa) & Conserved Motif & Zinc-Finger Type & Subcellular Location & Group \\
\hline SaWRKY5 & 549 & WRKYGQK/WRKYGQK & $\mathrm{C}-\mathrm{X}_{4}-\mathrm{C}-\mathrm{X}_{22}-\mathrm{HXH} / \mathrm{C}-\mathrm{X}_{4}-\mathrm{C}-\mathrm{X}_{23}-\mathrm{HXH}$ & Nucleus & I \\
\hline SaWRKY 8 & 273 & WRKYGQK & $\mathrm{C}-\mathrm{X}_{4}-\mathrm{C}-\mathrm{X}_{22}-\mathrm{HXH}$ & Golgi & I \\
\hline SaWRKY12 & 764 & WRKYGQK/WRKYGQK & $\begin{array}{c}\mathrm{C}-\mathrm{X}_{5-} \mathrm{C}-\mathrm{X}_{23}-\mathrm{HXT} / \mathrm{C}-\mathrm{X}_{4}-\mathrm{C}-\mathrm{X}_{22}-\mathrm{HXH} / \\
\mathrm{C}-\mathrm{X}_{4}-\mathrm{C}-\mathrm{X}_{23}-\mathrm{HXH}\end{array}$ & Nucleus & I \\
\hline SaWRKY18 & 700 & WRKYGQK/WRKYGQK & $\mathrm{C}-\mathrm{X}_{4}-\mathrm{C}-\mathrm{X}_{22}-\mathrm{HXH} / \mathrm{C}-\mathrm{X}_{4}-\mathrm{C}-\mathrm{X}_{23}-\mathrm{HXH}$ & Nucleus & I \\
\hline SaWRKY20 & 507 & WRKYGQK/WRKYGQK & $\mathrm{C}-\mathrm{X}_{4}-\mathrm{C}-\mathrm{X}_{22}-\mathrm{HXH} / \mathrm{C}-\mathrm{X}_{4}-\mathrm{C}-\mathrm{X}_{23}-\mathrm{HXH}$ & Nucleus & I \\
\hline SaWRKY25 & 342 & WRKYGQK & $\begin{array}{c}\mathrm{C}-\mathrm{X}_{4}-\mathrm{C}-\mathrm{X}_{22}-\mathrm{HXH} / \mathrm{C}-\mathrm{X}_{4}-\mathrm{C}-\mathrm{X}_{23}-\mathrm{HXH} / \\
\mathrm{C}-\mathrm{X}_{7}-\mathrm{C}-\mathrm{X}_{23}-\mathrm{HXL}\end{array}$ & Nucleus & I \\
\hline SaWRKY30 & 427 & WRKYGQK/WRKYGQK & $\mathrm{C}-\mathrm{X}_{4}-\mathrm{C}-\mathrm{X}_{22}-\mathrm{HXH} / \mathrm{C}-\mathrm{X}_{4}-\mathrm{C}-\mathrm{X}_{23}-\mathrm{HXH}$ & Nucleus & I \\
\hline SaWRKY31 & 443 & WRKYGQK/WRKYGQK & $\mathrm{C}-\mathrm{X}_{4}-\mathrm{C}-\mathrm{X}_{22}-\mathrm{HXH} / \mathrm{C}-\mathrm{X}_{4}-\mathrm{C}-\mathrm{X}_{23}-\mathrm{HXH}$ & Nucleus & I \\
\hline SaWRKY34 & 580 & WRKYGQK/WRKYGQK & $\mathrm{C}-\mathrm{X}_{4}-\mathrm{C}-\mathrm{X}_{22}-\mathrm{HXH} / \mathrm{C}-\mathrm{X}_{4}-\mathrm{C}-\mathrm{X}_{23}-\mathrm{HXH}$ & Nucleus & I \\
\hline SaWRKY36 & 440 & WRKYGQK/WRKYGQK & $\mathrm{C}-\mathrm{X}_{4}-\mathrm{C}-\mathrm{X}_{22}-\mathrm{HXH} / \mathrm{C}-\mathrm{X}_{4}-\mathrm{C}-\mathrm{X}_{23}-\mathrm{HXH}$ & Nucleus & I \\
\hline SaWRKY38 & 511 & WRKYGQK/WRKYGQK & $\mathrm{C}-\mathrm{X}_{4}-\mathrm{C}-\mathrm{X}_{22}-\mathrm{HXH} / \mathrm{C}-\mathrm{X}_{4}-\mathrm{C}-\mathrm{X}_{23}-\mathrm{HXH}$ & Nucleus & I \\
\hline SaWRKY39 & 521 & WRKYGQK/WRKYGQK & $\mathrm{C}-\mathrm{X}_{4}-\mathrm{C}-\mathrm{X}_{22}-\mathrm{HXH} / \mathrm{C}-\mathrm{X}_{4}-\mathrm{C}-\mathrm{X}_{23}-\mathrm{HXH}$ & Nucleus & I \\
\hline SaWRKY41 & 621 & WRKYGQK/WRKYGQK & $\mathrm{C}-\mathrm{X}_{4}-\mathrm{C}-\mathrm{X}_{22}-\mathrm{HXH} / \mathrm{C}-\mathrm{X}_{5}-\mathrm{C}-\mathrm{X}_{23}-\mathrm{HXH}$ & Nucleus & I \\
\hline SaWRKY 44 & 627 & WRKYGQK/WRKYGQK & $\mathrm{C}-\mathrm{X}_{4}-\mathrm{C}-\mathrm{X}_{22}-\mathrm{HXH} / \mathrm{C}-\mathrm{X}_{4}-\mathrm{C}-\mathrm{X}_{23}-\mathrm{HXH}$ & Nucleus & I \\
\hline SaWRKY55 & 577 & WRKYGQK/WRKYGQK & $\mathrm{C}-\mathrm{X}_{4}-\mathrm{C}-\mathrm{X}_{22}-\mathrm{HXH} / \mathrm{C}-\mathrm{X}_{4}-\mathrm{C}-\mathrm{X}_{23}-\mathrm{HXH}$ & Nucleus & I \\
\hline SaWRKY1 & 333 & WRKYGQK & $\mathrm{C}-\mathrm{X}_{5}-\mathrm{C}-\mathrm{X}_{23}-\mathrm{HXH}$ & Nucleus & IIa \\
\hline SaWRKY3 & 320 & WRKYGQK & $\mathrm{C}-\mathrm{X}_{5}-\mathrm{C}-\mathrm{X}_{23}-\mathrm{HXH}$ & Nucleus & IIa \\
\hline SaWRKY49 & 369 & WRKYGQK & $\mathrm{C}-\mathrm{X}_{5}-\mathrm{C}-\mathrm{X}_{23}-\mathrm{HXH}$ & Chloroplast & IIa \\
\hline SaWRKY10 & 555 & WRKYGQK & $\mathrm{C}-\mathrm{X}_{5}-\mathrm{C}-\mathrm{X}_{23}-\mathrm{HXH}$ & Nucleus & $\mathrm{IIb}$ \\
\hline SaWRKY11 & 331 & WRKYGQK & $\mathrm{C}-\mathrm{X}_{6}-\mathrm{CX}_{23}-\mathrm{HXH}$ & Nucleus & $\mathrm{IIlb}$ \\
\hline SaWRKY17 & 639 & WRKYGQK & $\mathrm{C}-\mathrm{X}_{5}-\mathrm{C}-\mathrm{X}_{23}-\mathrm{HXH}$ & Nucleus & $\mathrm{IIb}$ \\
\hline SaWRKY24 & 545 & WRKYGQK & $\mathrm{C}-\mathrm{X}_{5}-\mathrm{C}-\mathrm{X}_{23}-\mathrm{HXH}$ & Nucleus & $\mathrm{IIb}$ \\
\hline SaWRKY35 & 435 & WRKYGQK & $\mathrm{C}-\mathrm{X}_{5}-\mathrm{C}-\mathrm{X}_{23}-\mathrm{HXH}$ & Nucleus & $\mathrm{IIb}$ \\
\hline SaWRKY40 & 631 & WRKYGQK & $\mathrm{C}-\mathrm{X}_{5}-\mathrm{C}-\mathrm{X}_{23}-\mathrm{HXH}$ & Nucleus & $\mathrm{IIb}$ \\
\hline SaWRKY2 & 179 & WRKYGQK & $\mathrm{C}-\mathrm{X}_{4}-\mathrm{C}-\mathrm{X}_{23}-\mathrm{HXH}$ & Nucleus & IIc \\
\hline SaWRKY4 & 329 & WRKYGQK & $\mathrm{C}-\mathrm{X}_{4}-\mathrm{C}-\mathrm{X}_{23}-\mathrm{HXH}$ & Nucleus & IIc \\
\hline SaWRKY13 & 295 & WRKYGQK & $\mathrm{C}-\mathrm{X}_{4}-\mathrm{C}-\mathrm{X}_{23}-\mathrm{HXH}$ & Nucleus & IIc \\
\hline SaWRKY15 & 306 & WRKYGQK & $\mathrm{C}-\mathrm{X}_{4}-\mathrm{C}-\mathrm{X}_{23}-\mathrm{HXH}$ & Nucleus & IIc \\
\hline SaWRKY16 & 199 & WRKYGQK & $\mathrm{C}-\mathrm{X}_{4}-\mathrm{C}-\mathrm{X}_{23}-\mathrm{HXH}$ & Nucleus & IIc \\
\hline SaWRKY19 & 296 & WRKYGQK & $\mathrm{C}-\mathrm{X}_{4}-\mathrm{C}-\mathrm{X}_{23}-\mathrm{HXH}$ & Nucleus & IIc \\
\hline SaWRKY23 & 234 & WRKYGQK & $\mathrm{C}-\mathrm{X}_{4}-\mathrm{C}-\mathrm{X}_{23}-\mathrm{HXH}$ & Nucleus & IIc \\
\hline SaWRKY27 & 266 & WRKYGQK & $\mathrm{C}-\mathrm{X}_{4}-\mathrm{C}-\mathrm{X}_{23}-\mathrm{HXH}$ & Nucleus & IIc \\
\hline SaWRKY29 & 181 & WRKYGKK & $\mathrm{C}-\mathrm{X}_{4}-\mathrm{C}-\mathrm{X}_{23}-\mathrm{HXH}$ & Nucleus & IIc \\
\hline SaWRKY32 & 311 & WRKYGQK & $\mathrm{C}-\mathrm{X}_{4}-\mathrm{C}-\mathrm{X}_{23}-\mathrm{HXH}$ & Nucleus & IIc \\
\hline SaWRKY33 & 343 & WRKYGQK & $\mathrm{C}-\mathrm{X}_{4}-\mathrm{C}-\mathrm{X}_{23}-\mathrm{HXH}$ & Nucleus & IIc \\
\hline
\end{tabular}


Table 1. Cont.

\begin{tabular}{|c|c|c|c|c|c|}
\hline Gene Name & ORF (aa) & Conserved Motif & Zinc-Finger Type & Subcellular Location & Group \\
\hline SaWRKY37 & 294 & WRKYGQK & $\mathrm{C}-\mathrm{X}_{4}-\mathrm{C}-\mathrm{X}_{23}-\mathrm{HXH}$ & Nucleus & IIc \\
\hline SaWRKY 45 & 121 & WRKYGHK & $\mathrm{C}-\mathrm{X}_{4}-\mathrm{C}-\mathrm{X}_{23}-\mathrm{HXY}$ & cytoplasm & IIc \\
\hline SaWRKY46 & 177 & WRKYGQK & $\mathrm{C}-\mathrm{X}_{4}-\mathrm{C}-\mathrm{X}_{23}-\mathrm{HXH}$ & peroxisome & IIc \\
\hline SaWRKY54 & 589 & WRKYGKK & $\mathrm{C}-\mathrm{X}_{4}-\mathrm{C}-\mathrm{X}_{23}-\mathrm{HXH}$ & Nucleus & IIc \\
\hline SaWRKY 62 & 341 & WRKYGQK & C-X4-C-X23-HXH & Nucleus & IIc \\
\hline SaWRKY22 & 356 & WRKYGQK & $\mathrm{C}-\mathrm{X}_{5}-\mathrm{C}-\mathrm{X}_{23}-\mathrm{HXH}$ & Nucleus & IId \\
\hline SaWRKY42 & 335 & WRKYGQK & $\mathrm{C}-\mathrm{X}_{4}-\mathrm{C}-\mathrm{X}_{22}-\mathrm{HXV} / \mathrm{C}-\mathrm{X}_{5}-\mathrm{C}-\mathrm{X}_{23}-\mathrm{HXH}$ & Nucleus & IId \\
\hline SaWRKY43 & 310 & WRKYGQK & $\mathrm{C}-\mathrm{X}_{5}-\mathrm{C}-\mathrm{X}_{23}-\mathrm{HXH}$ & Nucleus & IId \\
\hline SaWRKY50 & 375 & WRKYGQK & $\mathrm{C}-\mathrm{X}_{5}-\mathrm{C}-\mathrm{X}_{23}-\mathrm{HXH}$ & Nucleus & IId \\
\hline SaWRKY52 & 347 & WRKYGQK & $\mathrm{C}-\mathrm{X}_{5}-\mathrm{C}-\mathrm{X}_{23}-\mathrm{HXH}$ & Nucleus & IId \\
\hline SaWRKY59 & 314 & WRKYGQK & C-X5-C-X23-HXH & Nucleus & IId \\
\hline SaWRKY 60 & 314 & WRKYGQK & $\mathrm{C}-\mathrm{X}_{5}-\mathrm{C}-\mathrm{X}_{23}-\mathrm{HXH}$ & Nucleus & IId \\
\hline SaWRKY 61 & 315 & WRKYGQK & $\mathrm{C}-\mathrm{X}_{5}-\mathrm{C}-\mathrm{X}_{23}-\mathrm{HXH}$ & Nucleus & IId \\
\hline SaWRKY 64 & 336 & WRKYGQK & C-X5-C-X23-HXH & Nucleus & IId \\
\hline SaWRKY6 & 394 & WRKYGQK & $\mathrm{C}-\mathrm{X}_{5}-\mathrm{C}-\mathrm{X}_{23}-\mathrm{HXH}$ & Nucleus & IIe \\
\hline SaWRKY14 & 282 & WRKYGQK & $\mathrm{C}-\mathrm{X}_{5}-\mathrm{C}-\mathrm{X}_{23}-\mathrm{HXH}$ & Nucleus & $\mathrm{IIe}$ \\
\hline SaWRKY21 & 316 & WRKYGQK & $\mathrm{C}-\mathrm{X}_{5}-\mathrm{C}-\mathrm{X}_{23}-\mathrm{HXH}$ & Nucleus & IIe \\
\hline SaWRKY26 & 300 & WRKYGQK & $\mathrm{C}-\mathrm{X}_{5}-\mathrm{C}-\mathrm{X}_{23}-\mathrm{HXH}$ & Nucleus & IIe \\
\hline SaWRKY 48 & 242 & WRKYGQK & $\mathrm{C}-\mathrm{X}_{5}-\mathrm{C}-\mathrm{X}_{23}-\mathrm{HXH}$ & Nucleus & IIe \\
\hline SaWRKY51 & 369 & WRKYGQK & $\mathrm{C}-\mathrm{X}_{3}-\mathrm{C}-\mathrm{X}_{22}-\mathrm{HXL} / \mathrm{C}-\mathrm{X}_{5}-\mathrm{C}-\mathrm{X}_{23}-\mathrm{HXH}$ & Nucleus & IIe \\
\hline SaWRKY56 & 422 & WRKYGQK & $\mathrm{C}-\mathrm{X}_{5}-\mathrm{C}-\mathrm{X}_{23}-\mathrm{HXH}$ & Nucleus & IIe \\
\hline SaWRKY58 & 319 & WRKYGQK & C-X5-C-X22-HXS & Nucleus & IIe \\
\hline SaWRKY 63 & 334 & WRKYGQK & C-X5-C-X23-HXH & Nucleus & IIe \\
\hline SaWRKY7 & 367 & WRKYGQK & $\mathrm{C}-\mathrm{X}_{7}-\mathrm{C}-\mathrm{X}_{23}-\mathrm{HXC}$ & Nucleus & III \\
\hline SaWRKY9 & 357 & WRKYGQK & $\mathrm{C}-\mathrm{X}_{7}-\mathrm{C}-\mathrm{X}_{23}-\mathrm{HXC}$ & Nucleus & III \\
\hline SaWRKY 28 & 366 & WRKYGQK & $\mathrm{C}-\mathrm{X}_{7}-\mathrm{C}-\mathrm{X}_{23}-\mathrm{HXC}$ & Nucleus & III \\
\hline SaWRKY47 & 290 & WRKYGQK & $\mathrm{C}-\mathrm{X}_{7}-\mathrm{C}-\mathrm{X}_{23}-\mathrm{HXC}$ & Nucleus & III \\
\hline SaWRKY53 & 362 & WRKYGQK & C-X7-C-X22-HXT & Nucleus & III \\
\hline SaWRKY57 & 330 & WRKYGQK & $\mathrm{C}-\mathrm{X}_{7}-\mathrm{C}-\mathrm{X}_{23}-\mathrm{HXC}$ & Nucleus & III \\
\hline
\end{tabular}

Based on a prediction by the PSORT program, the subcellular localization of most of the 64 SaWRKY proteins was in the nucleus, except for SaWRKY8, which was found in the Golgi apparatus, SaWRKY45 in the cytoplasm, SaWRKY46 in the peroxisome, and SaWRKY49 in the chloroplast (Table 1).

\subsection{Phylogenetic Analysis of SaWRKY Proteins}

To understand the evolutionary relationship between SaWRKY proteins, the 64 identified SaWRKY proteins was examined based on AtWRKY proteins from the three groups, and an unrooted tree was built by MEGA6.0 software using the NJ method (Figure 1). All 64 SaWRKY proteins were classified into three major groups (I, II and III) (Table 1, Figure 1). Among the 15 SaWRKY proteins in group I, 13 contained two WRKY domains and the remaining two SaWRKY proteins (SaWRKY8 and 25) contained only one WRKY domain (Table 1). There were 43 SaWRKY proteins with only one WRKY domain in group II, and these could be further divided into an additional five subgroups, i.e., IIa, IIb, IIc, IId, and IIe. SaWRKY7, 9, 28, 47, 53 and 57, which contained only one WRKY domain, formed group III (Table 1).

\subsection{Exon-Intron Organization of SaWRKY Genes}

To further understand the pivotal role that exon-intron structural features play in the evolution of S. album gene families, the structure of SaWRKY genes was obtained through exon-intron organization analysis. Among the 64 SaWRKY genes, three had one intron and two exons, 35 had two introns and three exons, six had three introns and four exons, nine had four introns and five exons, two had five introns and six exons, three had five introns and five exons, while the remaining SaWRKY 49 had six introns and seven exons, and SaWRKY 54 had 13 introns and 14 exons (Figure 2b). Of note, SaWRKY genes in the same subgroup had a similar intron and exon composition, such as two introns and three exons in group II, subgroups IId, IIe and group III, or four introns and five exons in subgroup IIb. SaWRKY54 had 14 exons, SaWRKY49 had seven exons, and SaWRKY2 and SaWRKY16 had only two exons. This indicates an occurrence of both exon gain and loss during evolution of the SaWRKY gene family, thus leading to functional diversity among SaWRKY genes. 


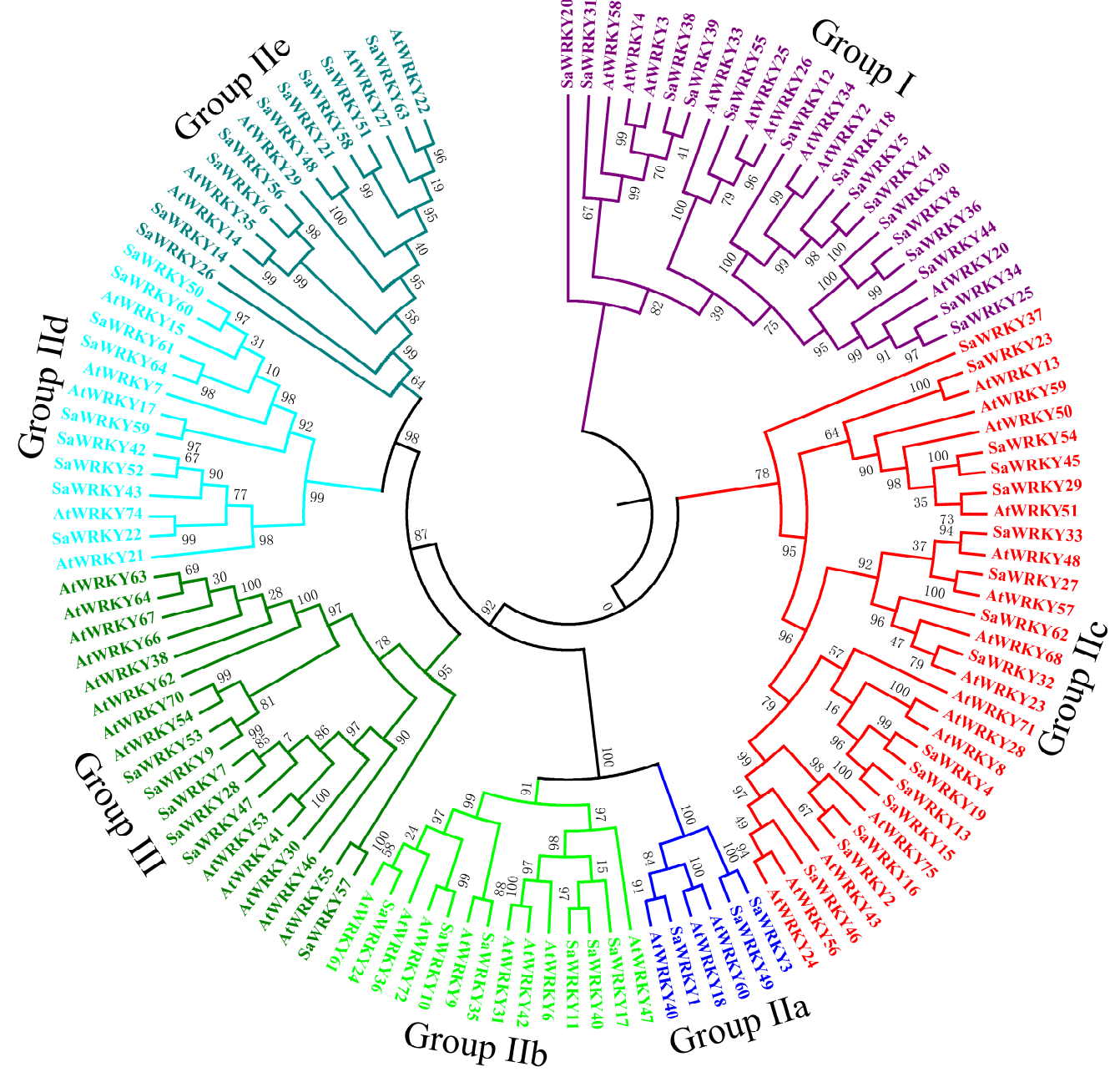

Figure 1. Phylogenetic tree of WRKY proteins from Santalum album and Arabidopsis thaliana. The 64 SaWRKY proteins and representative Arabidopsis WRKY proteins were aligned by ClustalX 2.0, and the NJ tree was constructed using MEGA6.0 with 1000 bootstrap replicates.

a

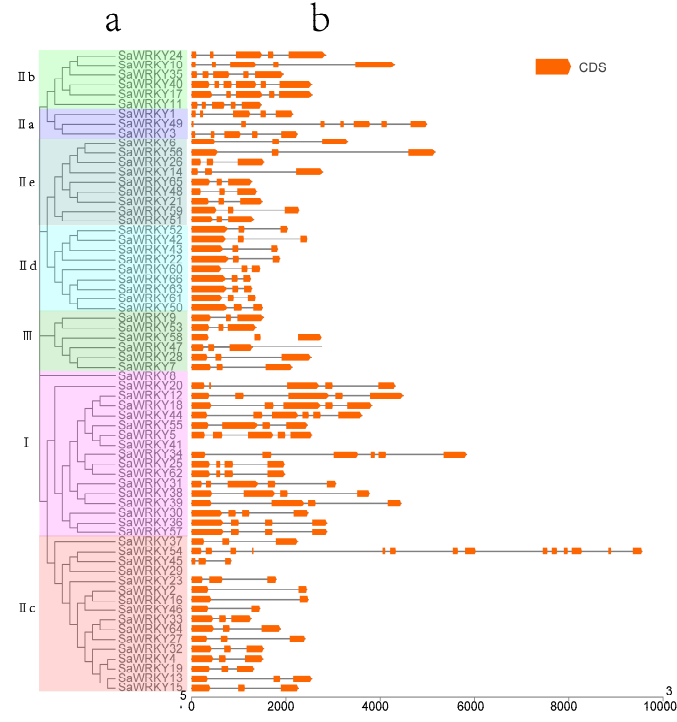

C

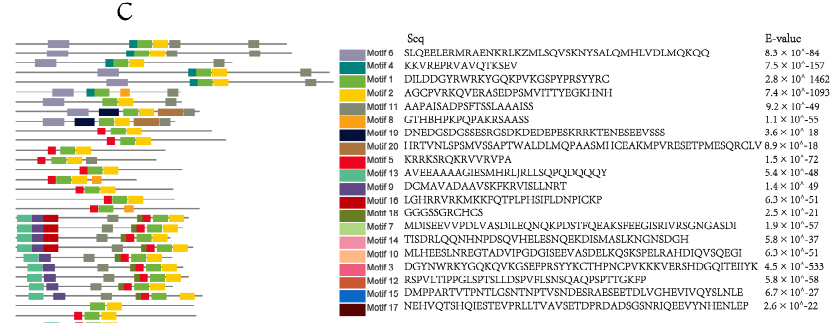

Figure 2. Schematic diagram showing the phylogenetic relationship among conserved motifs of SaWRKY proteins and gene structure of SaWRKY genes. The phylogenetic tree was built on the basis of the full amino acids of 64 SaWRKY proteins whose conserved motifs were identified using MEME. 


\subsection{Motif Composition of SaWRKY Proteins}

To gain insight into the functional regions of SaWRKY proteins, the MEME program was used to predict the composition of the 64 SaWRKY protein motifs. A total of 20 conserved motifs were detected (Figure 2c). Among them, motifs 1 and 3 contained the heptapeptide stretch WRKYGQK while all 64 SaWRKY proteins contained one or two WRKYGQK motifs. Motif 2 was the conserved zinc-finger structure at the C-terminal end and was found in 61 SaWRKY proteins, but not in SaWRKY8, 11 and 51 (Figure 2). Motif 9 was unique to all members of subgroup IId, motif 16 was unique to SaWRKY42, 43 and 52, and motif 17 was unique to SaWRKY30 and 36. Similar motif compositions were found in the same groups, especially in the same subgroups, such as in subgroups IIa or IIb.

\subsection{Prediction and Functional Enrichment Analysis of Potential SaWRKY Target Genes}

A total of 13,306 genes that contained at least one W-box in their putative promoters were identified in the assembled S. album genome. The number of genes decreased as more W-boxes were identified. Among all 13,306 genes, 2563 genes contained one W-box, 3007 genes contained two W-boxes, while 1328 genes contained at least five $\mathrm{W}$-boxes and were used for further pathway enrichment analysis using the Kyoto Encyclopedia of Genes and Genomes (KEGG) database. As shown in Figure 3, the top enriched KEGG pathways included plant-pathogen interactions, environmental adaption, metabolism and organismal systems. These results indicate that SaWRKY genes are closely involved in biotic and abiotic stress responses, as well as in other biological pathways.

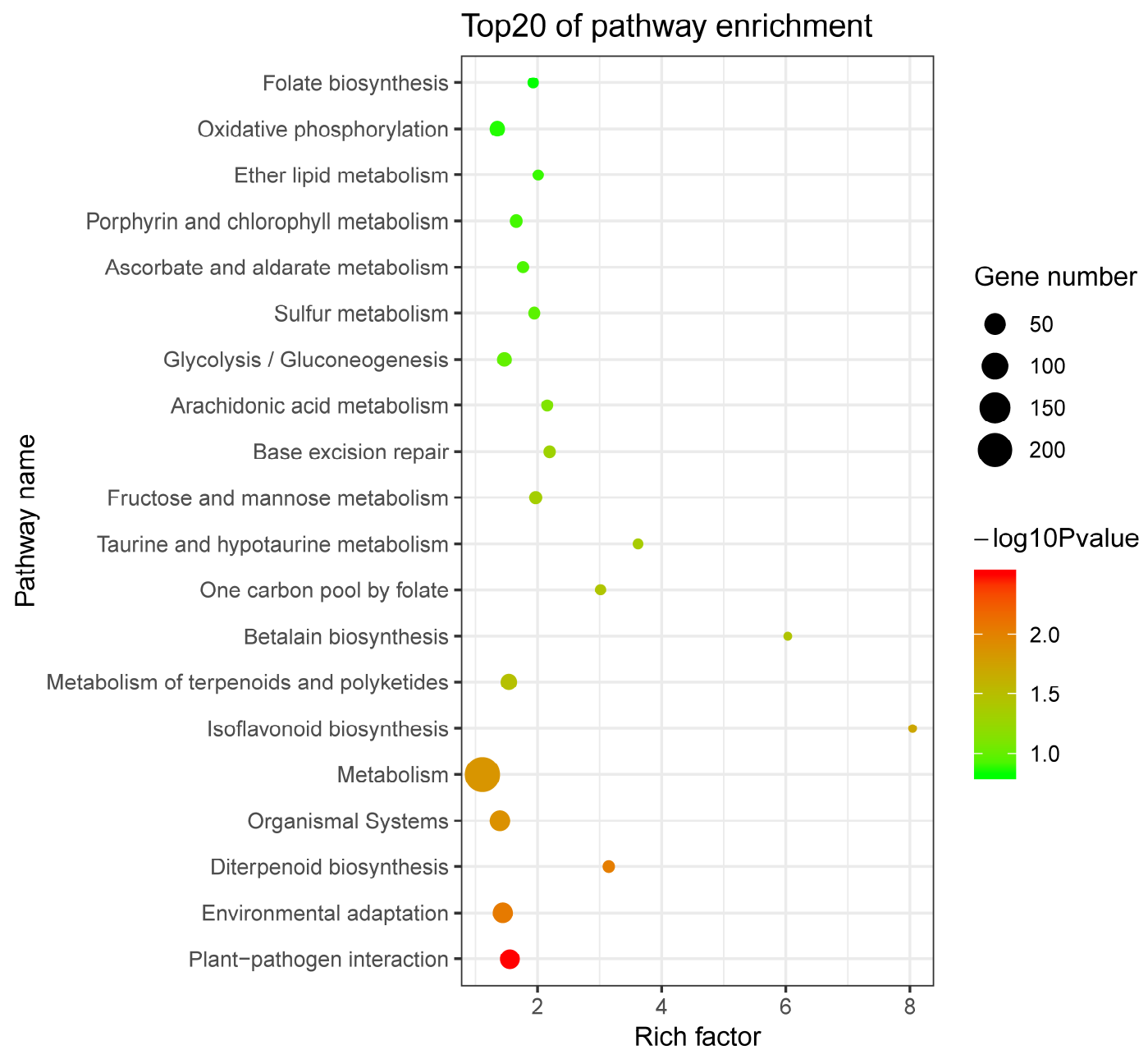

Figure 3. The 20 top Kyoto Encyclopedia of Genes and Genomes (KEGG) enrichment pathways of potential SaWRKY target genes with at least five W-boxes. 


\subsection{Expression Patterns of SaWRKY Genes in Different Tissues}

A gene expression pattern may reflect its biological function. To explore the possible functions of SaWRKY genes in S. album development, the expression patterns of 41 SaWRKY genes in various tissues (leaves, roots, heartwood, sapwood, and transition zone) were obtained from the transcriptome data (Figure 4). Five SaWRKY genes (SaWRKY16, 20, 22, 3, and 44) showed a higher expression level in wood tissue (heartwood, sapwood, and transition zone) than in leaves and roots. The expression of SaWRKY2, 15 and 27 occurred preferentially in heartwood. Higher levels of mRNA were observed in roots for SaWRKY4, 10, 26 and 34 while 12 SaWRKY genes (SaWRKY3, 5, 8, 9, 17, 21, 28, 29, 33, 36, 38 , and 41) showed a higher level of expression in leaves than in other tissues. SaWRKY $6,25,35$ and 37 had a low level of expression in all the tissues examined, while SaWRKY12, 30, 31, 39 and 42 had consistently high expression levels in all tissues (Figure 4). It was not possible to assess the expression level of 23 SaWRKY genes in all tissues from the transcriptome data.

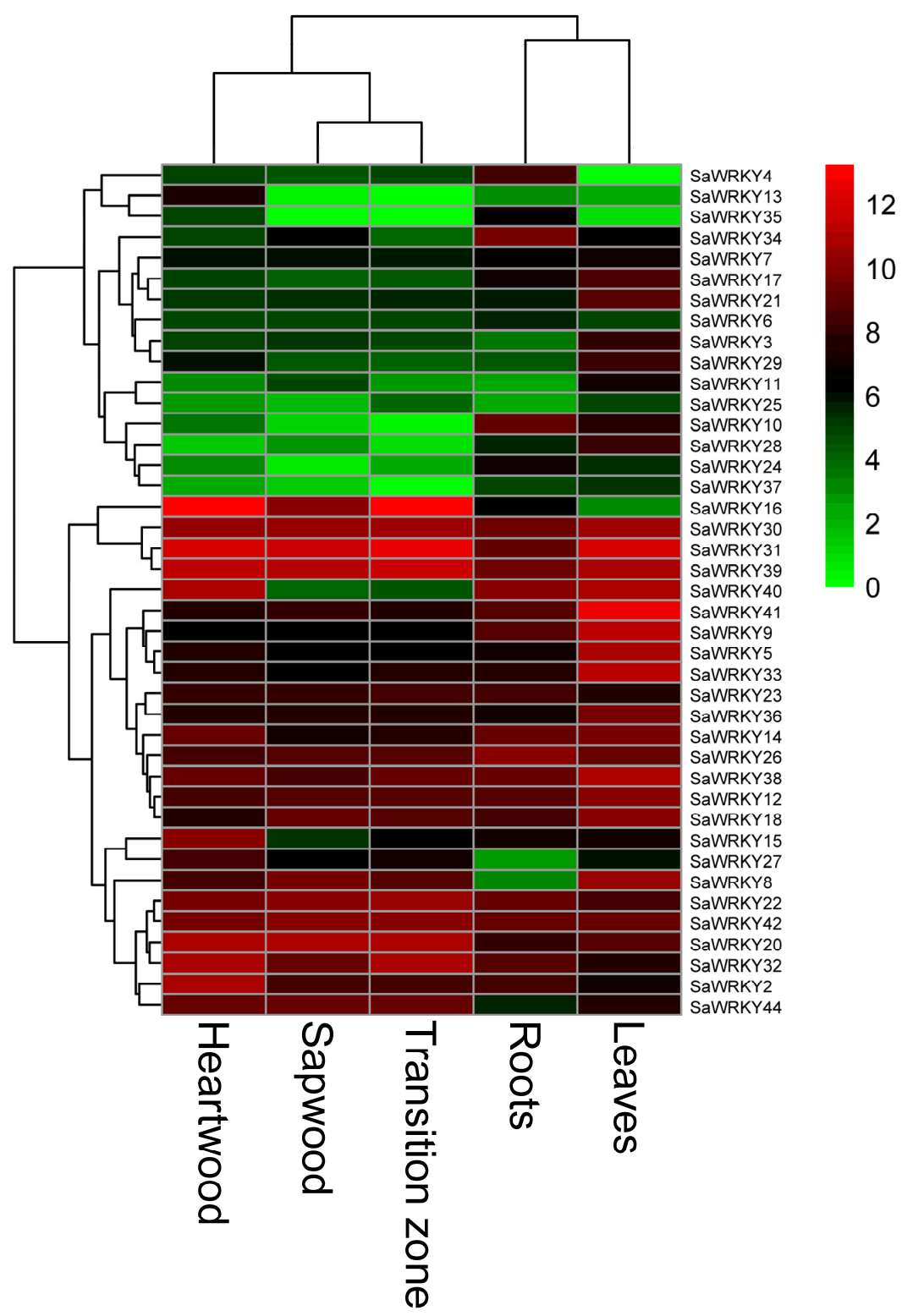

Figure 4. The expression patterns of 41 SaWRKY genes in five tissues of Santalum album. The heat map was generated based on the number of reads per kilobase of exon modelled per million mapped reads (RPKM) of transcriptome data. 


\subsection{Expression Profiles of SaWRKY Genes in Response to $S A$ and MeJA}

To detect whether the SaWRKY genes were induced by different hormones, RT-qPCR was performed to determine the expression levels of the $42 \mathrm{SaWRKY}$ genes when stimulated by SA and MeJA in callus. The data shows that 13 out of 42 SaWRKY genes were up-regulated by SA, namely SaWRKY1, 3, 7, 9, 11, 15, 24, 25, 28, 35, 37, 38 and 40 (Figure 5A, Table S2). In contrast, 12 SaWRKY genes were down-regulated by SA: SaWRKY4, 8, 12, 13, 21, 22, 26, 27, 30, 32, 34 and 36. Several SaWRKY genes were regulated by MeJA. Among them, SaWRKY1, 3, 4, 6, 7, 8, 11, 15, 16, 17, 20, 26, 29, 36, 38, 39, 40 and 42 were up-regulated, whereas, SaWRKY13, 23, 24, 25, 27 and 28 were down-regulated (Figure 5B, Table S3). Interestingly, seven SaWRKY genes (SaWRKY1, 3, 7, 11, 15, 38 and 40) were up-regulated both by SA and MeJA.

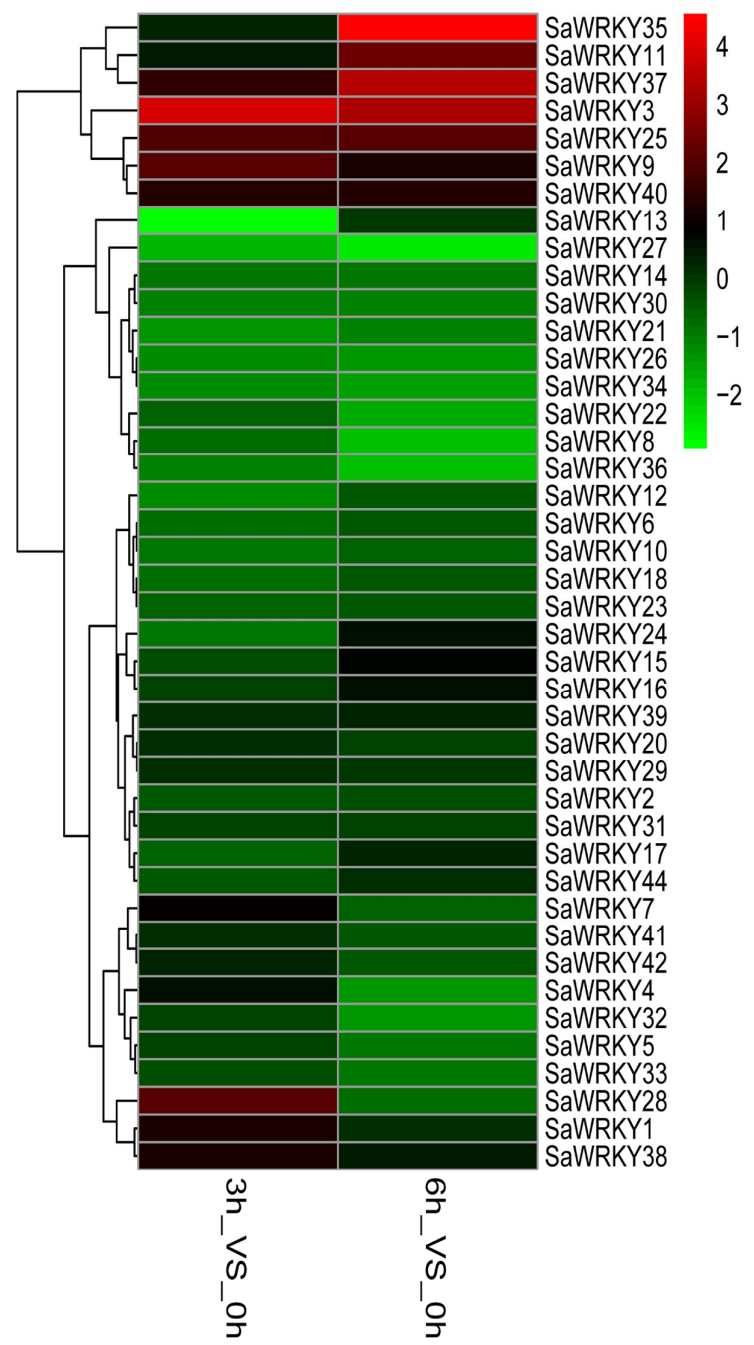

A

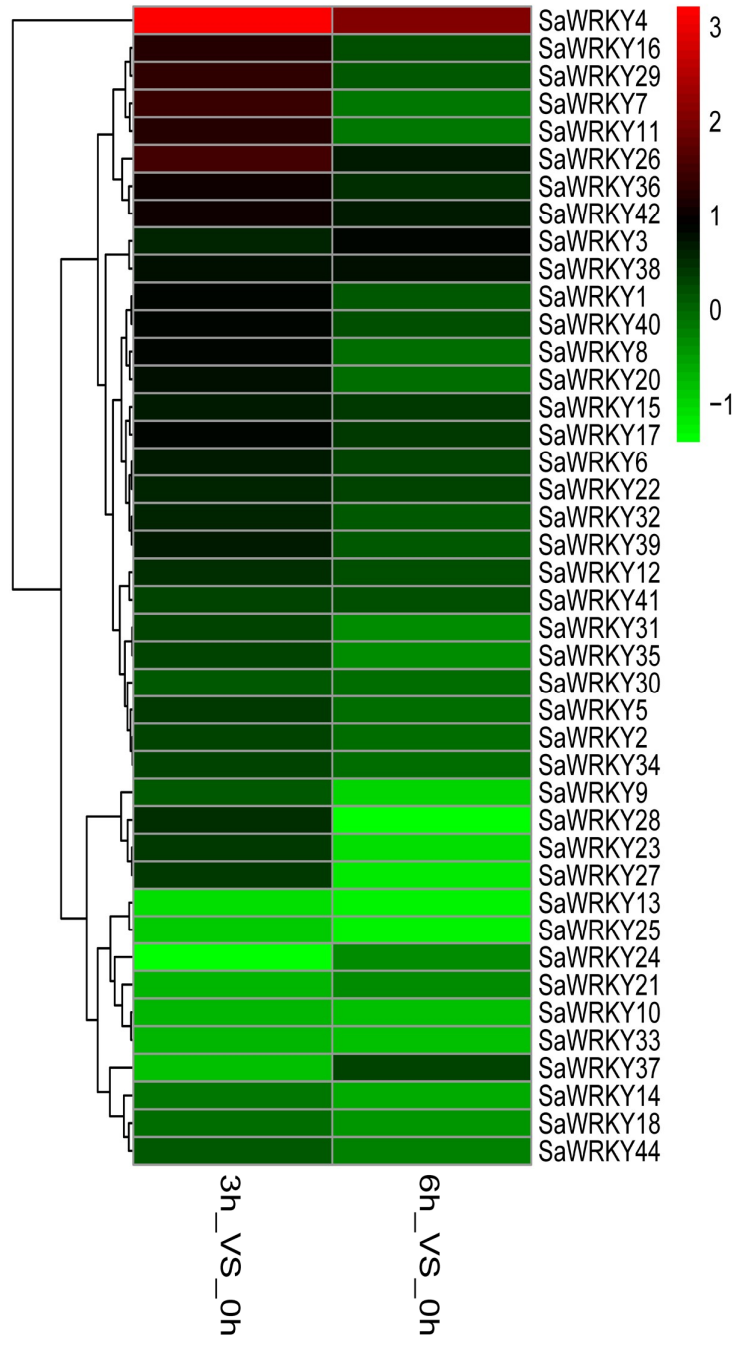

B

Figure 5. Expression profiles of SaWRKY genes following SA and MeJA treatments. The expression of 42 SaWRKY genes was determined under SA (A) and MeJA (B) stimuli at three time points $(0,3$, and $6 \mathrm{~h}$ ) in callus. The heat map was generated based on log2-transformed count value from RT-qPCR data using R language. RT-qPCR data were collected from three biological replicates.

\subsection{Characterization, Tissue Expression Patterns and Subcellular Localization of SaWRKY1}

As indicated above, the expression level of SaWRKY1 was not detected in five tissues from the transcriptome data. More interestingly, since SaWRKY1 is one of the genes that was up-regulated both by SA and MeJA, it was selected for further analysis. The full length of the coding nucleotide sequence 
of SaWRKY1 was $999 \mathrm{bp}$, encoding a protein of 332 amino acid residues with a predicted theoretical isoelectric point and protein molecular weight of 7.55 and $37.01 \mathrm{kD}$, respectively.

Tissue expression patterns, which were examined by RT-qPCR, showed that transcription of SaWRKY1 took place mainly in callus, leaves, and roots (Figure 6). The abundance of SaWRKY1 mRNA accumulated preferentially in callus (Figure 6).

The subcellular localization of the SaWRKY1 protein is most likely in the nucleus. To verify its subcellular location, a C-terminal YFP fusion construct for the SaWRKY1 protein and a nuclear location protein mCherry was co-transformed into Arabidopsis mesophyll protoplasts. The SaWRKY1-YFP fusion protein was localized in the nucleus and co-localized with mCherry (Figure 7), demonstrating that the SaWRKY1 protein is located in the nucleus, in accordance with its putative function as a TF.

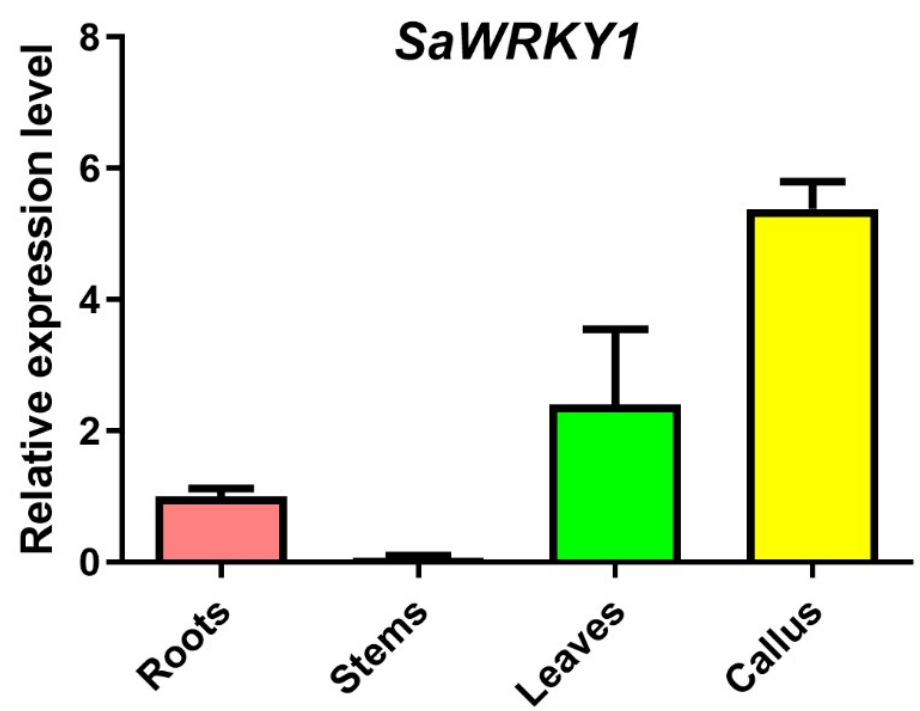

Figure 6. Expression of SaWRKY1 in different tissues of Santalum album. Relative expression levels of SaWRKY1 in four tissues were determined by RT-qPCR with three replicates. Values shown are means $\pm \mathrm{SE}$.

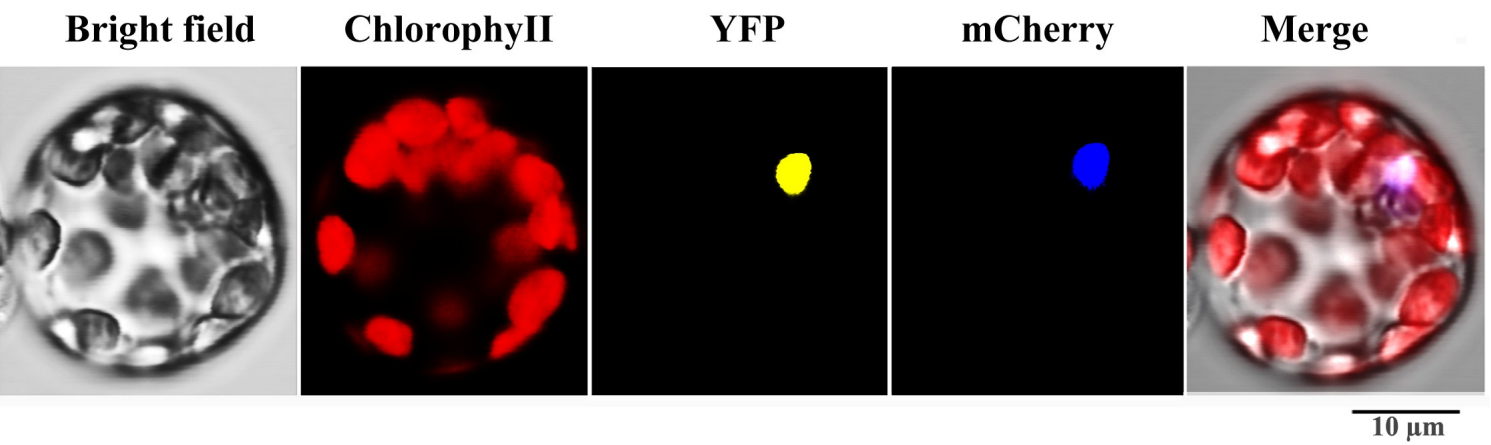

Figure 7. Subcellular localization assay of the SaWRKY1 protein.

\subsection{Overexpression of SaWRKY1 Enhances Salinity Tolerance in Transgenic Arabidopsis Plants}

SaWRKY1 was significantly induced both by SA and MeJA, indicating that it might be a node of convergence in signal transduction pathways mediated by SA and MeJA. To further explore the roles of SaWRKY1 in abiotic stress responses, the 35S: SaWRKY1: pCAMBIA1302 construct was transformed into $A$. thaliana, and two independent $\mathrm{T} 3$ homozygous progeny lines were used for further analysis.

In order to examine the role of SaWRKY1 in abiotic stress, the two A. thaliana transgenic lines, which showed the same level of germination, growth properties, and chlorophyll content (Figures $8 \mathrm{~A}$ and $9 \mathrm{~A}$ ), were randomly selected and irrigated with $300 \mathrm{mM} \mathrm{NaCl}$. After three days, both transgenic 
lines grew well but the wild type control showed obvious inhibited growth (Figure 8A,B; Figure 9A,B). The content of chlorophyll $a, b$, and $a+b$ in the wild type declined by $34.6 \%, 36.1 \%$ and $35.5 \%$, respectively compared with the content of each component averaged over the two transgenic lines (Figures 8B and 9B). When irrigated once again with $300 \mathrm{mM} \mathrm{NaCl}$, unlike the wild type plants which withered and nearly died, the 35S:WRKY1 transgenic lines showed little withering, had greener leaves and slightly inhibited growth after 5 days (Figure 8A-C). Accordingly, either the content of chlorophyll $a$ and $b$, or the total chlorophyll content was reduced by more than $80 \%$ in wild type $A$. thaliana compared to the content of each component in 35S:WRKY1 transgenic lines (Figures 8C and 9C).

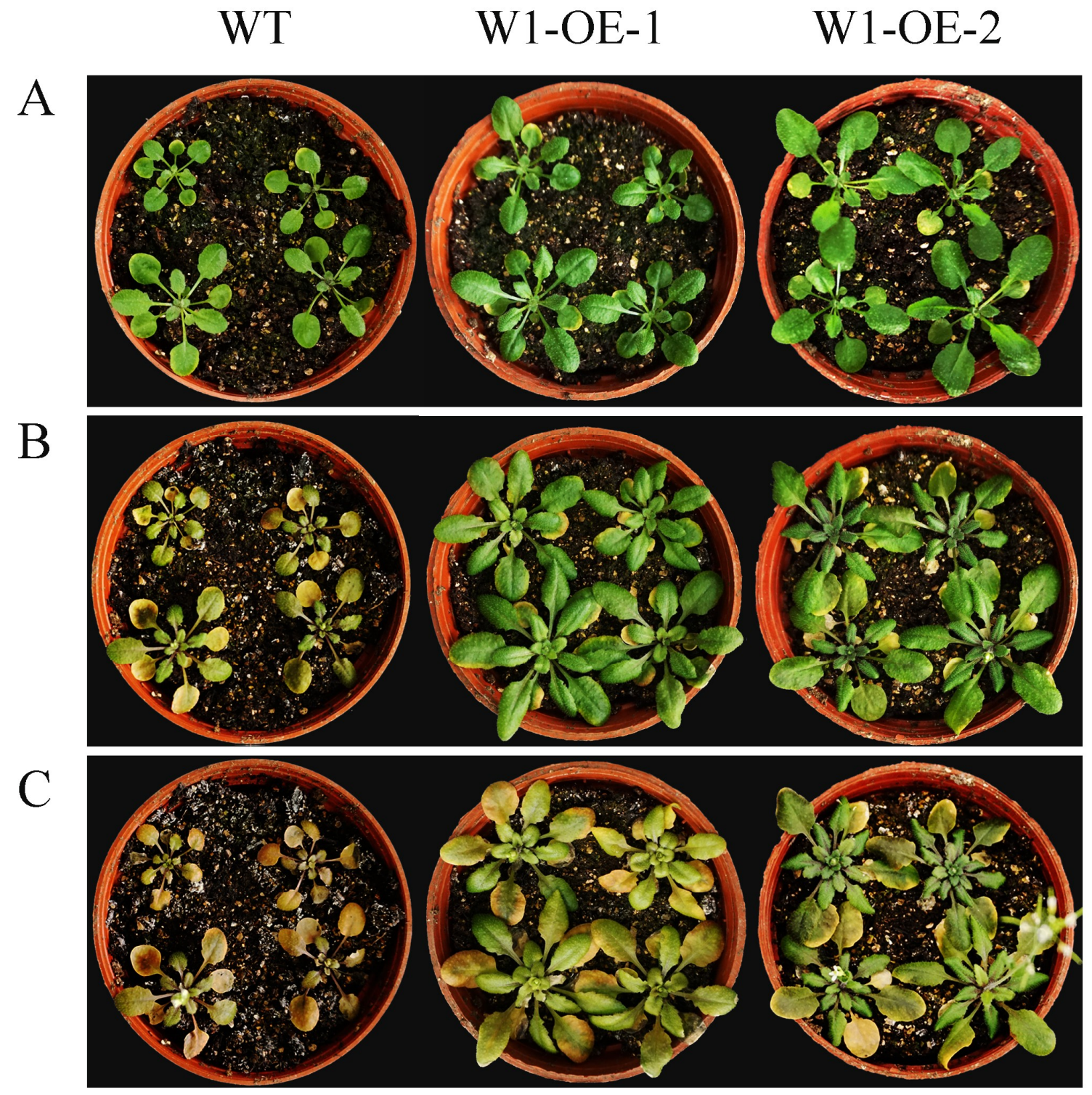

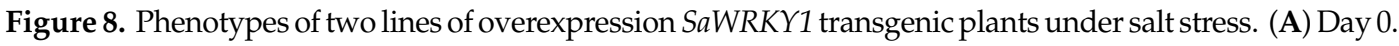
(B) Day 3 after irrigation with $300 \mathrm{mM} \mathrm{NaCl}$. (C) Day 5 after second irrigation with $300 \mathrm{mM} \mathrm{NaCl}$. 

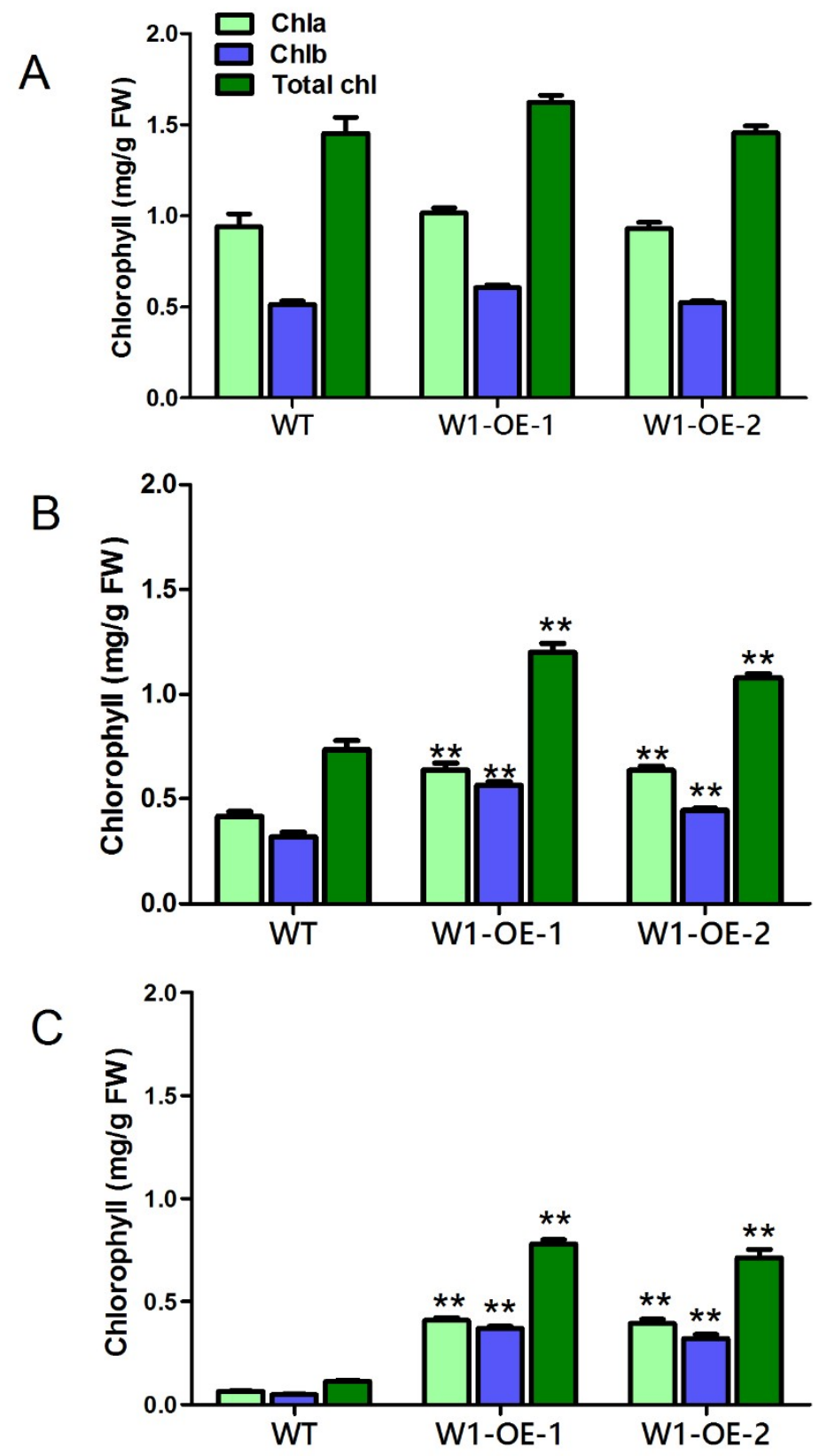

Figure 9. The chlorophyll content of two lines of overexpression SaWRKY1 transgenic plants under salt stress. All values are means \pm SE from at least three independent biological replicates $(8$ seedlings per replicate). Double asterisk $(* *)$ indicates significance at $p<0.01$ for each component between wild type and transgenic lines using Duncan's multiple range test. (A) Day 0. (B) Day 3 after irrigation with $300 \mathrm{mM} \mathrm{NaCl}$. (C) Day 5 after second irrigation with $300 \mathrm{mM} \mathrm{NaCl}$.

\section{Discussion}

As one of the largest TF families in flowering plants, the WRKY gene family participates in plant development as well as in response to abiotic and biotic stresses. Based on the S. album genome and transcriptome data, 64 SaWRKY genes were identified in our work, accounting for $100 \%$ of the S. album WRKY family genes that were determined by Mahesh et al. [30] using the sandalwood genome. A total of five SaWRKY genes (SaWRKY1, 19, 43, 45, and 64) were only found in the genome data but lacked transcriptome data sets, either because these genes might have a lower level of expression in some tissues while others might be pseudogenes. Three SaWRKY genes (SaWRKY8, 29 and 41) was only found in transcriptome data, which may be caused by incomplete genome assembling or 
alternative splicing. The 64 SaWRKY proteins identified could be divided into three groups based on a phylogenetic analysis for A. thaliana and S. album. Group II, which contained 43 SaWRKY proteins, was further divided into five subgroups (IIa, IIb, IIc, IId, and IIe), accounting for the largest proportion $(67 \%)$ among all the groups. Other plant species showed a comparable proportion, namely $58 \%$ in A. thaliana [6], 64\% in Caragana intermedia [31], and 66\% in cassava (Manihot esculenta) [32]. Chimeric proteins such as R protein-WRKY (RW) genes are a feature of some WRKY family genes in switchgrass (Panicum virgatum), sorghum (Sorghum bicolor) and rice (Oryza sativa) [11]. We searched for 64 SaWRKY proteins, and no other domains except for WDs and zinc-finger motifs were found. This suggest that RW genes may be a characteristic of some monocot genomes.

Publicly available transcriptome datasets were processed to obtain the RPKM expression values for the 41 SaWRKY genes in five different tissues of S. album. The heat map (Figure 4) generated using these expression values exhibited different expression patterns for all the identified SaWRKY genes except for $S a W R K Y 1$ in the five tissues, indicating that they may perform diversified functions in plant development or in response to stress. SaWRKY12, 30, 31, 39, and 42 shared similarly high expression levels in all the tested tissues (Figure 4), indicating that these genes may play essential roles in S. album tissue development. In contrast, four SaWRKY genes (SaWRKY6, 25, 35, and 37) showed a low level of expression in all five tissues and may thus have a limited function in their development. Several SaWRKY genes that were identified showed higher tissue-specific expression patterns, i.e., SaWRKY2, 15, 20, 22, 27, 32 and 44, which were preferentially expressed in wood tissue (sapwood, transition zone and heartwood) (Figure 4). In particular, four of these genes (SaWRKY16, 20, 22, and 32) accumulated obviously higher levels of mRNA in the transition zone, which is the main location of the synthesis of valuable sandal essential oil [21]. For now, it can be speculated that several of these genes may be involved in essential oil biosynthesis, although this will require extensive additional analyses. In addition, RT-qPCR was performed to detect the levels of SaWRKY1 expression in roots, stems (wood tissue), leaves and callus (Figure 6). SaWRKY1 mRNA mainly accumulated in the leaves, roots and callus, showing the highest expression level in fast-growing tissue (i.e., callus).

Due to their sessile lifestyle, plants must adjust to various biotic and abiotic stresses [33]. Phytohormones play a central role in a plant's ability to integrate various environmental stimuli or cues with the genetic program in their life cycles [34]. Among several phytohormones, JA and SA play crucial roles in orchestrating different stress responses within a plant, such as in pathogen defense [35], or protection against abiotic stresses (drought, low temperature, and salinity) [36]. Increasing evidence shows that the expression levels of plant WRKY genes are regulated by different plant hormones, such as $37 V v W R K Y$ genes that were induced by SA, and $48 V v W R K Y$ genes that were regulated following JA treatment in grape (Vitis vinifera) [37], or 55 PtrWRKY genes that were induced by SA and MeJA treatment in poplar (Populus trichocarpa and P. tomentosa) [9]. It is difficult to conduct basic research in woody plants because of their slow growth, so callus is a useful and efficient system to conduct gene function research on plants such as oil palm (Elaeis guineensis) [38] and apple (Malus x domestica) [39]. In order to detect the expression levels of the SaWRKY genes in response to SA and MeJA, RT-qPCR was performed in callus generated from newly sprouted S. album shoots. RT-qPCR results showed 13 up-regulated and 12 down-regulated SaWRKY genes after SA treatment (Figure 5A, Table S2), and 18 up-regulated and six down-regulated SaWRKY genes after JA treatment (Figure 5B, Table S3). This indicates that these genes may be involved in biotic and abiotic stress responses mediated by SA- and/or JA-dependent defense signaling pathways. AtWRKY53, a paralogous gene of SaWRKY7 and SaWRKY28 in S. album, was significantly induced in five- and seven-week-old A. thaliana plants sprayed with $2 \mathrm{mM} \mathrm{SA} \mathrm{[40].} \mathrm{AtWRKY53} \mathrm{expression} \mathrm{was} \mathrm{up-regulated} \mathrm{after} \mathrm{pathogen} \mathrm{attack} \mathrm{[41],}$ and this gene participates in the regulation of senescence, being positively regulated by SA signaling and negatively regulated by JA signaling [40,42], and negatively regulates drought tolerance via controlled stomatal movement independent of abscisic acid levels [43]. It can thus be inferred that paralogous genes $S a W R K Y 7$ and 28 may perform a similar function in S. album. A member of subgroup IIc, SaWRKY16, which showed the highest level of expression in the transition zone of wood tissue, 
was significantly induced by JA (Figure 5B, Table S3). Its paralogous gene, AtWRKY75, played a positive role in the defense of $A$. thaliana against pathogens (including Pectobacterium carotovorum ssp. carotovorum and Sclerotinia sclerotiorum) and oxalic acid stress, and was mainly dependent on the JA/ethylene pathway [44,45]. Two SaWRKY genes (SaWRKY25 and 28) were up-regulated by SA but down-regulated by JA (Figure 5A,B; Tables S2 and S3), consistent with some reports showing that SA and JA function antagonistically [46-48]. Conversely, seven SaWRKY genes, SaWRKY1, 3, 7, 11, 15, 38 and 40, were up-regulated when stimulated by SA and JA. SaWRKY1 was one of the genes induced both by SA and JA treatment, and its overexpression strengthened salt tolerance and increased the content of chlorophyll $a, b$, and $a+b$ in transgenic $A$. thaliana plants compared to the wild type. Plants often enhance the content of non-enzymatic compounds such as chlorophyll to improve tolerance to salt stress, and a rich literature on this topic illustrates that SA and JA perform important roles in these processes. For example, strawberry (Fragaria $\times$ ananassa) plants treated with $1.0 \mathrm{mM} \mathrm{SA}$ had a higher chlorophyll content and showed better growth under salt stress than unstressed plants [49]. The application of $0.01 \mathrm{mM} \mathrm{SA}$ to tomato (Solanum lycopersicum) plants caused the accumulation of photosynthetic pigments and soluble sugars, and enhanced plant growth and development under salt stress [50]. Foliar application of $2.0 \mathrm{mM} \mathrm{JA}$ to wheat seedlings enhanced their salt stress tolerance and growth by increasing the activity of antioxidant enzymes and the content of glutathione, chlorophyll $b$ and carotenoids [51]. Cumulatively, these findings coincide with our results and suggest that SaWRKY1 improves plant salt tolerance by increasing the content of photosynthetic pigments, probably mediated by SA and/or JA. However, the accurate regulatory mechanism still needs to be studied in further detail. In A. thaliana, the paralogous genes of SaWRKY1, 3 and 49, namely AtWRKY18, 40 and 60 , are evolutionarily closely related WRKY domain TFs. Based on multiple alignments of amino acid sequences (Figure S1), there was $36.02 \%, 40.82 \%$ and $33.87 \%$ identity between SaWRKY1 and AtWRKY18, 40, and 60, respectively. SaWRKY1 has the closest evolutionary relationship and highest amino acid sequence identity with AtWRKY40, which is also involved in salt stress [52], suggesting that these paralogous genes play similar roles in plants against abiotic stress and confirming that SaWRKY1 plays a regulatory role in salt resistance. Thus, SaWRKY1 may be useful in engineering salinity tolerance of S. album trees via Agrobacterium- or gene gun-mediated transformation of callus. As two members of subgroup IIa, SaWRKY3 and SaWRKY 49 might also be involved in SA- and JA-mediated pathogen and salt stress responses, but the putative function needs to be further investigated.

\section{Materials and Methods}

\subsection{Plant Materials and Hormone Treatments}

The leaves, roots and stems were collected from three seven-year-old S. album trees growing in South China Botanical Garden. Callus was induced from newly sprouted shoots following previously reported methods $[25,53]$, with a few modifications, as described next. Shoot segments were inoculated on solid Murashige and Skoog (MS) basal medium [54] to which $1.0 \mathrm{mg} / \mathrm{L}$ thidiazuron (TDZ) was added to induce callus. The resulting callus was proliferated on solid MS medium supplemented with $1.5 \mathrm{mg} / \mathrm{L}$ 2,4-dichlorophenoxyacetic acid (2,4-D) and $0.2 \mathrm{mg} / \mathrm{L}$ TDZ. After about 20 days, similarly good callus (Figure S2) was proliferated after transferring into liquid MS basal medium for 20 days then shaken continuously at $100 \mathrm{rpm}$ under the same culture conditions. After $24 \mathrm{~h}$, SA and MeJA were added separately at a final concentration of $100 \mu \mathrm{M}$ each. Samples were collected at 0,3 and $6 \mathrm{~h}$ with three biological triplicates per treatment. All samples were frozen immediately in liquid nitrogen (N2) and stored at $-80^{\circ} \mathrm{C}$ until use.

\subsection{Identification of WRKY Genes in S. album and Prediction of Subcellular Localization}

The S. album genome was downloaded from the National Center for Biotechnology Information (NCBI) (GCA_002925775.1) and then annotated using sandalwood transcriptome sequencing data and genome sequence data from maize, rice and Arabidopsis by a web service for training AUGUSTUS and 
predicting genes in eukaryotes (WebAUGUSTUS; https://bio.tools/webaugustus). S. album transcriptome sequencing data was downloaded from the NCBI Sequence Read Archive (SRA) (GenBank accessions: PRJNA297453, SRA150639, SRR3731808, and SRR3731809), and the AtWRKY gene sequences were searched and downloaded from The Arabidopsis Information Resource (TAIR) website (http://www. arabidopsis.org/index.jsp). All the S. album WRKY genes were identified following He et al. [55]. In brief, candidate $S a W R K Y$ genes were obtained by searching $S$. album protein sequences using the hidden Markov model (http://hmmer.janelia.org/). Putative SaWRKY genes were further verified for the presence of the PFAM domain (PF03106) in the pFAM database (http://pfam.xfam.org/) and then screened for the WRKY motif and zinc-finger domains, and finally confirmed as SaWRKY genes after removing redundant sequences by CD-HIT software (see Table S1). The subcellular localization of SaWRKY genes was predicted using the PSORT program (https://psort.hgc.jp/).

\subsection{Construction of Phylogenetic Tree and Conserved Motif Analysis of SaWRKY Proteins}

An unrooted phylogenetic tree of S. album and Arabidopsis WRKY proteins was constructed using MEGA6.0 software with 1000 bootstrap replicates. The parameters used to construct trees were: gaps/missing data: complete deletion; substitution model: maximum composite likelihood; rates among sites: gamma distributed with invariant sites $(G)$.

The online program MEME $\mathrm{v}$ 4.11.2 (http://meme.nbcr.net/meme/) was used to analyze conserved motifs for the 64 S. album WRKY protein sequences. MEME parameters were set as advised by He et al. [55]. The TBtool was used to draw a schematic diagram of the conserved motifs and gene structures.

\subsection{Identification and Functional Enrichment Analysis of Potential SaWRKY Target Genes}

The 2-k DNA sequence upstream of the ATG start codon of each gene assembled from the S. album genome was used to scan the WRKY TF binding site element with the sequence $(C / T) T G A C(C / T)$. The SaWRKY genes with at least five WRKY binding sites were identified as potential SaWRKY target genes, and were used for further pathway enrichment analysis using the KEGG database. The top 20 enrichment KEGG pathways were drawn with R package ggplot2.

\subsection{Gene Expression Analysis by Quantitative real-Time PCR (RT-qPCR)}

Total RNA from S. album callus was isolated using the Eastep ${ }^{\circledR}$ Super Total RNA Extraction kit (Promega, Shanghai, China), and the RNA from leaves, stems and roots was extracted using a protocol reported for the isolation of RNA from woody plants [56]. The quality and quantity of DNA-free total RNA was assessed using a NanoDrop ND-1000 spectrophotometer (Nanodrop Technologies, Wilmington, NC, USA). RNA samples with an A260/A280 ratio between 1.9 and 2.1 and an A260/A230 ratio greater than 2.0 were used for subsequent analysis. RNA integrity was assessed by $1.5 \%(w / v)$ agarose gel electrophoresis. Total RNA $(1 \mu \mathrm{g})$ was used to synthesize first-strand cDNAs using an equivalent amount of oligo-(dT)15 and random primers in $20 \mu \mathrm{L}$ volume with the GoScript ${ }^{\mathrm{TM}}$ Reverse Transcriptase system (Promega, Madison, WI, USA) according to the manufacturer's protocols. Amplification was performed at $25^{\circ} \mathrm{C}$ for $5 \mathrm{~min}, 42^{\circ} \mathrm{C}$ for $60 \mathrm{~min}$, and $70^{\circ} \mathrm{C}$ for $15 \mathrm{~min}$. The successfully synthesized cDNA samples were diluted 1:10 with nuclease-free water and stored at $-20^{\circ} \mathrm{C}$ until further use.

RT-qPCR was performed in 96-well plates in an ABI 7500 Real-time system (ABI, Alameda, CA, USA) using the SoAdvancedTM Universal SYBR ${ }^{\circledR}$ Green Supermix detection system (Bio-Rad, Hercules, CA, USA). The RT-qPCR reaction in a total volume of $10 \mu \mathrm{L}$ consisted of $5 \mu \mathrm{L}$ SYBR ${ }^{\circledR}$ Green Supermix, $0.5 \mu \mathrm{L}$ of forward primer $(10 \mu \mathrm{M}), 0.5 \mu \mathrm{L}$ of reverse primer $(10 \mu \mathrm{M}), 1 \mu \mathrm{L}$ of cDNA, and $3 \mu \mathrm{L}$ of $\mathrm{ddH}_{2} \mathrm{O}$. The cycling conditions were $95^{\circ} \mathrm{C}$ for $2 \mathrm{~min}$, followed by 40 cycles at $95^{\circ} \mathrm{C}$ for $15 \mathrm{~s}$ and $60^{\circ} \mathrm{C}$ for $1 \mathrm{~min}$. After 40 cycles, melting curve analysis was performed ranging from 60 to $95{ }^{\circ} \mathrm{C}$. The internal reference genes used in different tissues and phytohormone treatments followed Yan et al. [57], i.e., FAB1A and PP2C for four tissues, ODD and Fbp 1 for the SA treatment, as well as $C S A$ and Fbp3 for the MeJA treatment. The relative gene expression level was calculated using the 
$2^{-\Delta \Delta C q}$ method. All RT-qPCR experiments were carried out using three biological replicates of each sample. The gene-specific primers used for RT-qPCR are listed in Table S4.

\subsection{Cluster Analysis of Expression Data}

For the expression profiles of all putative SaWRKY genes in different tissues including leaves, roots and wood (containing heartwood, sapwood and the transition zone), the data that was obtained from the NCBI SRA database was mapped with SaWRKY gene nucleotide sequences using TopHat version 2.0.8. The level of gene expression was calculated by reads per kilobase of exon model per million mapped reads (RPKM), and the expression profiles via a heat map were calculated from the $\log 2(\mathrm{FPKM}+1)$ value, and shown as a green-black-red gradient by using the heat map package in $\mathrm{R}$ version 3.4.0. Expression $(\mathrm{Cq})$ values of the 42 putative SaWRKY genes at each time point in SA and MeJA treatments were determined using RT-qPCR. The expression profiles were generated by a heat map using $R$ language based on the $\log 2\left(2^{-\Delta \Delta C q}\right)$ value. Up- and down-regulated genes were defined as those showing more than a 1.5 -fold change or lower than a 0.5 -fold change, respectively $(p<0.05)$.

\subsection{Cloning and Subcellular Localization of SaWRKY1}

RACE was performed to obtain the full-length sequence of SaWRKY1 using the SMARTer RACE cDNA Amplification Kit (Takara Bio USA, Inc., Mountain View, CA, USA; see Method S1, Figure S3). The amplification product was sequenced at the Beijing Genomics Institute (BGI, Shenzhen, China), and then submitted to NCBI (accession number: MG655189). The theoretical isoelectric point and protein molecular weight were determined using ExPASy server (https://web.expasy.org/cgi-bin/protparam/ protparam).

The full-length coding sequence of SaWRKY1 without the termination codon was amplified with gene-specific primers (SaWRKY1YFPF, 5'-GAACGATAGCCATGGCAATGGATTACTCTTCTTGGAC3'; SaWRKY1YFPR, 5'-TGAGTCCGGACCATGGTAAATT TTTCATTTTGACTTT-3') and then fused to yellow fluorescent protein (YFP) behind the Cauliflower mosaic virus (CaMV) $35 \mathrm{~S}$ promoter in the NcoI site of the pSAT6-EYFP-N1 vector following the In-Fusion HD Cloning Kit (Clontech) instructions. The 35S: SaWRKY1: pSAT6-EYFP-N1 construct was confirmed by sequencing and then co-transformed with a nuclear location protein mCherry into $A$. thaliana mesophyll protoplasts according to a protocol described by Yoo et al. [58]. After $12 \mathrm{~h}$ incubation at $22{ }^{\circ} \mathrm{C}$ under light conditions, YFP fluorescence was visualized with a Zeiss LSM 510 confocal microscope (Zeiss, Jena, Germany), and images were captured using the same software.

\subsection{Arabidopsis thaliana Transformation and Salinity Stress}

The full-length coding sequence of SaWRKY1 was amplified with gene-specific primers (SaWRKY1OXF, 5' -GGACTCTTGACCATGGTAATGGATTACTCTTCTTGGACGGC-3'; SaWRKY1OXR, 5'-GTCAGATCTACCATGGTAAATTTTTCATTTTGACTTT-3') and then cloned into the pCAMBIA1302 vector behind the CaMV $35 \mathrm{~S}$ promoter in the $\mathrm{NcoI}$ site using the In-Fusion HD Cloning Kit. The resulting 35S: SaWRKY1: $p$ CAMBIA1302 construct, which was confirmed by sequencing and then transformed into Agrobacterium tumefaciens EHA105 using the freeze-thaw method described by Weigel and Glazebrook [59], was introduced into $A$. thaliana by the floral dip method [60]. Seeds of the $\mathrm{T}_{0}$ generation were collected from transgenic Arabidopsis. Thereafter, transformants were screened on half-strength MS medium containing $25 \mathrm{mg} / \mathrm{L}$ hygromycin. A total of 28 individual hygromycin-resistant plants, which developed two main leaves and roots, were obtained. Their transgenic nature was confirmed by RT-PCR with gene-specific primers (F: 5'-ATGGATTACTCTTCTTGGACGGC-3'; R: 5'-TCAAAATTTTTCATTTTGACTTT-3') using their own genomic DNA as template. The seeds of 26 transgenic hygromycin-resistant $\mathrm{T}_{1}$ generation plants containing the full-length coding sequence of SaWRKY1 were harvested separately from each individual plant. The 26 transgenic hygromycin-resistant plants were considered as 26 independent transgenic lines, which were further screened as mentioned above separately. Eight independent transgenic lines which showed a Mendelian ratio of about 3:1 
were selected to harvest $T_{2}$ generation seeds from each plant. These eight lines were further screened as mentioned above, and two independent transgenic lines that did not segregate were selected to harvest $\mathrm{T}_{3}$ generation seeds from each plant. RT-qPCR was performed using gene-specific primers (SaWRKY1qPCRF/R see Table S4) to confirm the expression of SaWRKY1 in two lines of $\mathrm{T}_{3}$ homozygous transformed plants (Figure S4). Two SaWRKY1 overexpression transgenic lines from the homozygous T3 generation, which were about 4 weeks old, were irrigated with $300 \mathrm{mM} \mathrm{NaCl}$ at three-day intervals to observe their phenotypes and to determine chlorophyll content using aqueous acetone as the solvent, as described by Porra et al. [61]. On the same dates, A. thaliana ecotype Columbia (Col-0) was also watered with $300 \mathrm{mM} \mathrm{NaCl}$ and used as the control. Experiments were performed at least three times to observe resulting phenotypes and to determine chlorophyll content.

\subsection{Statistical Analyses}

Statistical analysis was performed using SPSS 19.0 (IBM Corp., Armonk, NY, USA). Following one-way analysis of variance (ANOVA), significance between treatment means was assessed by Duncan's multiple range test at $p<0.05$ and $p<0.01$.

\section{Conclusions}

In this study, we identified 64 SaWRKY genes in Indian sandalwood based on genome and transcriptome data. The phylogenetic relationships, composition of conserved motifs and tissue expression patterns of these genes were analyzed. Callus was used to efficiently detect the expression profiles of 42 SaWRKY genes under different phytohormone treatments, suggesting that 25 and 24 SaWRKY genes are involved in SA- and MeJA-mediated abiotic or biotic response pathways, respectively. In addition, functional analysis of SaWRKY1 under salt stress increased our understanding of the roles that $S a W R K Y 1$ play in abiotic stress.

Supplementary Materials: Supplementary materials can be found at http://www.mdpi.com/1422-0067/20/22/ 5676/s1.

Author Contributions: G.M. conceived and designed the experiment. H.Y. and Y.X. performed the experiments. M.L. performed bioinformatics analyses. H.Y., J.W. and J.A.T.d.S. wrote the manuscript. J.A.T.d.S. provided critical analysis of the design and data. All authors read and approved the final manuscript.

Funding: This work was financially supported by the National Natural Science Foundation of China (grant numbers 31470685, 31270720, and 31100498), the Natural Science Foundation of Guangdong Province (S2012010009025), and the Guangdong Science and Technology project (2015B020231008). The funding agencies had no role in the design, analysis, and interpretation of the data, or writing of the manuscript.

Acknowledgments: The authors wish to thank Xinhua Zhang and Yuan Li for their revision suggestions, and thank Yueya Zhang, Hanzhi Liang, Beiyi Guo and Meiyun Niu for their technical assistance.

Conflicts of Interest: The authors declare that they have no conflict of interests.

\section{References}

1. Riechmann, J.L.; Heard, J.; Martin, G.; Reuber, L.; Jiang, C.-Z.; Keddie, J.; Adam, L.; Pineda, O.; Ratcliffe, O.J.; Samaha, R.R.; et al. Arabidopsis transcription factors: Genome-Wide comparative analysis among eukaryotes. Science 2000, 290, 2105-2110. [CrossRef]

2. Ulker, B.; Somssich, I.E. WRKY transcription factors: From DNA binding towards biological function. Curr. Opin. Plant Biol. 2004, 7, 491-498. [CrossRef]

3. Pan, Y.J.; Cho, C.C.; Kao, Y.Y.; Sun, C.H. A novel WRKY-Like protein involved in transcriptional activation of cyst wall protein genes in Giardia lamblia. J. Biol. Chem. 2009, 284, 17975-17988. [CrossRef] [PubMed]

4. Jin, J.; Tian, F.; Yang, D.C.; Meng, Y.Q.; Kong, L.; Luo, J.; Gao, G. PlantTFDB 4.0: Toward a central hub for transcription factors and regulatory interactions in plants. Nucleic Acids Res. 2017, 45, D1040-D1045. [CrossRef] [PubMed] 
5. Ishiguro, S.; Nakamura, K. Characterization of a cDNA encoding a novel DNA-binding protein, SPF1, that recognizes SP8 sequences in the 5 ' upstream regions of genes coding for sporamin and $\beta$-amylase from sweet potato. Mol. Gen. Genet. 1994, 244, 563-571. [CrossRef] [PubMed]

6. Eulgem, T.; Rushton, P.; Robatzek, S.; Somssich, I.E. The WRKY superfamily of plant transcription factors. Trends Plant Sci. 2000, 5, 199-206. [CrossRef]

7. Ross, C.A.; Liu, Y.; Shen, Q.J. The WRKY gene family in rice (Oryza sativa). J. Integr. Plant Biol. 2007, 49, 827-842. [CrossRef]

8. Schmutz, J.; Cannon, S.B.; Schlueter, J.; Ma, J.; Mitros, T.; Nelson, W.; Hyten, D.L.; Song, Q.; Thelen, J.J.; Cheng, J.; et al. Genome sequence of the palaeopolyploid soybean. Nature. 2010, 463, 178-183. [CrossRef] [PubMed]

9. Jiang, Y.; Duan, Y.; Yin, J.; Ye, S.; Zhu, J.; Zhang, F.; Lu, W.; Fan, D.; Luo, K. Genome-Wide identification and characterization of the Populus WRKY transcription factor family and analysis of their expression in response to biotic and abiotic stresses. J. Exp. Bot. 2014, 65, 6629-6644. [CrossRef]

10. Rushton, P.J.; Somssich, I.E.; Ringler, P.; Shen, Q.J. WRKY transcription factors. Trends Plant Sci. 2010, 15, $247-258$. [CrossRef]

11. Rinerson, C.I.; Scully, E.D.; Palmer, N.A.; Donze-Reiner, T.; Rabara, R.C.; Tripathi, P.; Shen, Q.J.; Sattler, S.E.; Rohila,J.S.; Sarath, G.; et al. The WRKY transcription factor family and senescence in switchgrass. BMC Genom. 2015, 16, 912. [CrossRef] [PubMed]

12. Lai, Z.; Vinod, K.; Zheng, Z.; Fan, B.; Chen, Z. Roles of Arabidopsis WRKY3 and WRKY4 transcription factors in plant responses to pathogens. BMC Plant Biol. 2008, 8, 68. [CrossRef] [PubMed]

13. Kim, K.C.; Lai, Z.; Fan, B.; Chen, Z. Arabidopsis WRKY38 and WRKY62 transcription factors interact with histone deacetylase 19 in basal defense. Plant Cell 2008, 20, 2357-2371. [CrossRef]

14. Liu, X.Q.; Bai, X.Q.; Qian, Q.; Wang, X.J.; Chen, M.S.; Chu, C.C. OsWRKY03, a rice transcriptional activator that functions in defense signaling pathway upstream of OsNPR1. Cell Res. 2005, 15, 593-603. [CrossRef] [PubMed]

15. Ramamoorthy, R.; Jiang, S.Y.; Kumar, N.; Venkatesh, P.N.; Ramachandran, S. A comprehensive transcriptional profiling of the WRKY gene family in rice under various abiotic and phytohormone treatments. Plant Cell Physiol. 2008, 49, 865-879. [CrossRef] [PubMed]

16. Chen, L.; Song, Y.; Li, S.; Zhang, L.; Zou, C.; Yu, D. The role of WRKY transcription factors in plant abiotic stresses. Biochim. Biophys. Acta 2012, 1819, 120-128. [CrossRef]

17. Ding, Z.J.; Yan, J.Y.; Li, G.X.; Wu, Z.C.; Zhang, S.Q.; Zheng, S.J. WRKY41 controls Arabidopsis seed dormancy via direct regulation of $A B I 3$ transcript levels not downstream of ABA. Plant J. 2014, 79, 810-823. [CrossRef]

18. Guan, Y.; Meng, X.; Khanna, R.; LaMontagne, E.; Liu, Y.; Zhang, S. Phosphorylation of a WRKY transcription factor by MAPKs is required for pollen development and function in Arabidopsis. PLoS Genet. 2014, 10, e1004384. [CrossRef]

19. Devaiah, B.N.; Karthikeyan, A.S.; Raghothama, K.G. WRKY75 transcription factor is a modulator of phosphate acquisition and root development in Arabidopsis. Plant Physiol. 2007, 143, 1789-1801. [CrossRef]

20. Jiang, Y.; Liang, G.; Yang, S.; Yu, D. Arabidopsis WRKY57 functions as a node of convergence for jasmonic acid- and auxin-mediated signaling in jasmonic acid-induced leaf senescence. Plant Cell 2014, 26, 230-245. [CrossRef]

21. Jones, C.G.; Keeling, C.I.; Ghisalberti, E.L.; Barbour, E.L.; Plummer, J.A.; Bohlmann, J. Isolation of cDNAs and functional characterisation of two multi-product terpene synthase enzymes from sandalwood, Santalum album L. Arch. Biochem. Biophys. 2008, 477, 121-130. [CrossRef] [PubMed]

22. Kim, T.H.; Ito, H.; Hayashi, K.; Hasegawa, T.; Machiguchi, T.; Yoshida, T. Aromatic constituents from the heartwood of Santalum album L. Chem. Pharm. Bull. 2005, 53, 641-644. [CrossRef] [PubMed]

23. Baldovini, N.; Delasalle, C.; Joulain, D. Phytochemistry of the heartwood from fragrant Santalum species: A review. Flavour Fragr. J. 2011, 26, 7-26. [CrossRef]

24. Rashkow, E.D. Perfumed the axe that laid it low: The endangerment of sandalwood in southern India. Indian Econ. Soc. Hist. Rev. 2014, 51, 41-70. [CrossRef]

25. Teixeira da Silva, J.A.; Kher, M.M.; Soner, D.; Page, T.; Zhang, X.; Nataraj, M.; Ma, G. Sandalwood: Basic biology, tissue culture, and genetic transformation. Planta 2016, 243, 847-887. [CrossRef] [PubMed] 
26. Zhang, X.; Teixeira da Silva, J.A.; Niu, M.; Li, M.; He, C.; Zhao, J.; Zeng, S.; Duan, J.; Ma, G. Physiological and transcriptomic analyses reveal a response mechanism to cold stress in Santalum album L. leaves. Sci. Rep. 2017, 7, 42165. [CrossRef]

27. Teixeira da Silva, J.A.; Kher, M.M.; Soner, D.; Nataraj, M.; Dobránszki, J.; Millar, M.A. Santalum molecular biology: Molecular markers for genetic diversity, phylogenetics and taxonomy, and genetic transformation. Agrofor. Syst. 2017, 9, 1301-1315. [CrossRef]

28. Zhang, X.; Berkowitz, O.; Teixeira da Silva, J.A.; Zhang, M.; Ma, G.; Whelan, J.; Duan, J. RNA-Seq analysis identifies key genes associated with haustorial development in the root hemiparasite Santalum album. Front. Plant Sci. 2015, 6, 661. [CrossRef]

29. Celedon, J.M.; Chiang, A.; Yuen, M.M.; Diaz-Chavez, M.L.; Madilao, L.L.; Finnegan, P.M.; Barbour, E.L.; Bohlmann, J. Heartwood-Specific transcriptome and metabolite signatures of tropical sandalwood (Santalum album) reveal the final step of (Z)-santalol fragrance biosynthesis. Plant J. 2016, 86, 289-299. [CrossRef]

30. Mahesh, H.B.; Subba, P.; Advani, J.; Shirke, M.D.; Loganathan, R.M.; Chandana, S.L.; Shilpa, S.; Chatterjee, O.; Pinto, S.M.; Prasad, T.S.K.; et al. Multi-omics driven assembly and annotation of the sandalwood (Santalum album) genome. Plant Physiol. 2018, 176, 2772-2788. [CrossRef]

31. Wan, Y.; Mao, M.; Wan, D.; Yang, Q.; Yang, F.; Mandlaa; Li, G.; Wang, R. Identification of the WRKY gene family and functional analysis of two genes in Caragana intermedia. BMC Plant Biol. 2018, 18, 31. [CrossRef] [PubMed]

32. Wei, Y.; Shi, H.; Xia, Z.; Tie, W.; Ding, Z.; Yan, Y.; Wang, W.; Hu, W.; Li, K. Genome-wide identification and expression analysis of the WRKY gene family in cassava. Front Plant Sci. 2016, 7, 25. [CrossRef] [PubMed]

33. Ahuja, I.; de Vos, R.C.; Bones, A.M.; Hall, R.D. Plant molecular stress responses face climate change. Trends Plant Sci. 2010, 15, 664-674. [CrossRef] [PubMed]

34. Santner, A.; Estelle, M. Recent advances and emerging trends in plant hormone signalling. Nature. 2009, 459, 1071-1078. [CrossRef] [PubMed]

35. Halim, V.A.; Vess, A.; Scheel, D.; Rosahl, S. The role of salicylic acid and jasmonic acid in pathogen defence. Plant Biol. 2006, 8, 307-313. [CrossRef]

36. Miura, K.; Tada, Y. Regulation of water, salinity, and cold stress responses by salicylic acid. Front Plant Sci. 2014, 5, 4. [CrossRef]

37. Guo, C.; Guo, R.; Xu, X.; Gao, M.; Li, X.; Song, J.; Zheng, Y.; Wang, X. Evolution and expression analysis of the grape (Vitis vinifera L.) WRKY gene family. J. Exp. Bot. 2014, 65, 1513-1528. [CrossRef]

38. Low, E.T.; Alias, H.; Boon, S.H.; Shariff, E.M.; Tan, C.Y.; Ooi, L.C.; Cheah, S.C.; Raha, A.R.; Wan, K.L.; Singh, R. Oil palm (Elaeis guineensis Jacq.) tissue culture ESTs: Identifying genes associated with callogenesis and embryogenesis. BMC Plant Biol. 2008, 8, 62. [CrossRef]

39. Dong, Q.L.; Liu, D.D.; An, X.H.; Hu, D.G.; Yao, Y.X.; Hao, Y.J. MdVHP1 encodes an apple vacuolar H+-PPase and enhances stress tolerance in transgenic apple callus and tomato. J. Plant Physiol. 2011, 168, 2124-2133. [CrossRef]

40. Miao, Y.; Zentgraf, U. The antagonist function of Arabidopsis WRKY53 and ESR/ESP in leaf senescence is modulated by the jasmonic and salicylic acid equilibrium. Plant Cell 2007, 19, 819-830. [CrossRef]

41. Murray, S.L.; Ingle, R.A.; Petersen, L.N.; Denby, K.J. Basal resistance against Pseudomonas syringae in Arabidopsis involves WRKY53 and a protein with homology to a nematode resistance protein. Mol. PlantMicrobe Interact. 2007, 20, 1431-1438. [CrossRef] [PubMed]

42. Zentgraf, U.; Laun, T.; Miao, Y. The complex regulation of WRKY53 during leaf senescence of Arabidopsis thaliana. Eur. J. Cell Biol. 2010, 89, 133-137. [CrossRef] [PubMed]

43. Sun, Y.; Yu, D. Activated expression of AtWRKY53 negatively regulates drought tolerance by mediating stomatal movement. Plant Cell Rep. 2015, 34, 1295-1306. [CrossRef] [PubMed]

44. Chen, X.; Liu, J.; Lin, G.; Wang, A.; Wang, Z.; Lu, G. Overexpression of AtWRKY28 and AtWRKY75 in Arabidopsis enhances resistance to oxalic acid and Sclerotinia sclerotiorum. Plant Cell Rep. 2013, 32, 1589-1599. [CrossRef]

45. Choi, C.; Park, Y.H.; Kwon, S.I.; Yun, C.; Ahn, I.; Park, S.R.; Hwang, D.-J. Identification of AtWRKY75 as a transcriptional regulator in the defense response to Pcc through the screening of Arabidopsis activation-tagged lines. Plant Biotechnol. Rep. 2013, 8, 183-192. [CrossRef]

46. Kunkel, B.N.; Brooks, D.M. Cross talk between signaling pathways in pathogen defense. Curr. Opin. Plant Biol. 2002, 5, 325-331. [CrossRef] 
47. Mur, L.A.; Kenton, P.; Atzorn, R.; Miersch, O.; Wasternack, C. The outcomes of concentration-specific interactions between salicylate and jasmonate signaling include synergy, antagonism, and oxidative stress leading to cell death. Plant Physiol. 2006, 140, 249-262. [CrossRef]

48. Mur, L.A.; Prats, E.; Pierre, S.; Hall, M.A.; Hebelstrup, K.H. Integrating nitric oxide into salicylic acid and jasmonic acid/ethylene plant defense pathways. Front Plant Sci. 2013, 4, 215. [CrossRef]

49. Karlidag, H.; Yildirim, E.; Turan, M. Salicylic acid ameliorates the adverse effect of salt stress on strawberry. Sci. Agric. 2009, 66, 180-187. [CrossRef]

50. Wasti, S.; Mimouni, H.; Smiti, S.; Zid, E.; Ben Ahmed, H. Enhanced salt tolerance of tomatoes by exogenous salicylic acid applied through rooting medium. OMICS 2012, 16, 200-207. [CrossRef]

51. Qiu, Z.; Guo, J.; Zhu, A.; Zhang, L.; Zhang, M. Exogenous jasmonic acid can enhance tolerance of wheat seedlings to salt stress. Ecotoxicol. Environ. Saf. 2014, 104, 202-208. [CrossRef] [PubMed]

52. Chen, H.; Lai, Z.; Shi, J.; Xiao, Y.; Chen, Z.; Xu, X. Roles of arabidopsis WRKY18, WRKY40 and WRKY60 transcription factors in plant responses to abscisic acid and abiotic stress. BMC Plant Biol. 2010, 10, 281. [CrossRef] [PubMed]

53. Singh, C.K.; Raj, S.R.; Jaiswal, P.S.; Patil, V.R.; Punwar, B.S.; Chavda, J.C.; Subhash, N. Effect of plant growth regulators on in vitro plant regeneration of sandalwood (Santalum album L.) via organogenesis. Agrofor. Syst. 2015, 90, 281-288. [CrossRef]

54. Murashige, T.; Skoog, F. A revised medium for rapid growth and bioassays with tobacco tissue cultures. Physiol. Plant. 1962, 15, 473-497. [CrossRef]

55. He, C.; Teixeira da Silva, J.A.; Tan, J.; Zhang, J.; Pan, X.; Li, M.; Luo, J.; Duan, J. A genome-wide identification of the WRKY family genes and a survey of potential WRKY target genes in Dendrobium officinale. Sci. Rep. 2017, 7, 9200. [CrossRef] [PubMed]

56. Kolosova, N.; Miller, B.; Ralph, S.; Ellis, B.E.; Douglas, C.; Ritland, K.; Bohlmann, J. Isolation of high-quality RNA from gymnosperm and angiosperm trees. BioTechniques 2004, 36, 821-824. [CrossRef]

57. Yan, H.; Zhang, Y.; Xiong, Y.; Chen, Q.; Liang, H.; Niu, M.; Guo, B.; Li, M.; Zhang, X.; Li, Y.; et al. Selection and validation of novel RT-qPCR reference genes under hormonal stimuli and in different tissues of Santalum album. Sci. Rep. 2018, 8, 17511. [CrossRef]

58. Yoo, S.D.; Cho, Y.H.; Sheen, J. Arabidopsis mesophyll protoplasts: A versatile cell system for transient gene expression analysis. Nat. Protoc. 2007, 2, 1565-1572. [CrossRef]

59. Weigel, D.; Glazebrook, J. Transformation of Agrobacterium using the freeze-thaw method. CSH Protoc. 2006, 7, 1031-1036. [CrossRef]

60. Zhang, X.; Henriques, R.; Lin, S.S.; Niu, Q.W.; Chua, N.H. Agrobacterium-mediated transformation of Arabidopsis thaliana using the floral dip method. Nat. Protoc. 2006, 1, 641-646. [CrossRef]

61. Porra, R.J.; Thompson, W.A.; Kriedemann, P.E. Determination of accurate extinction coefficients and simultaneous equations for assaying chlorophylls $a$ and $b$ extracted with four different solvents: Verification of the concentration of chlorophyll standards by atomic absorption spectroscopy. Biochim. Biophys. Acta 1989, 975, 384-394. [CrossRef]

(C) 2019 by the authors. Licensee MDPI, Basel, Switzerland. This article is an open access article distributed under the terms and conditions of the Creative Commons Attribution (CC BY) license (http://creativecommons.org/licenses/by/4.0/). 